\title{
A importância de Leo Waibel para a geografia brasileira e o início das relações científicas entre o Brasil e a Alemanha no campo da geografia
}

Gerd Koblhepp

Instituto de Geografia da Eberhard Karls Universität Tübingen, Alemanha

Recebido: 04/02/2013 Versão revisada (entregue): 29/11/2013 Aprovado: 03/12/2013

\begin{abstract}
Resumo
O tema deste artigo é a relevância do geógrafo alemão Leo Waibel para a geografia brasileira. Nascido em fins do século XIX, Waibel teve uma trajetória acadêmica singular. Doutorou-se, sob a orientação de Alfred Hettner, na prestigiosa Universidade de Heidelberg. Obteve sua livre-docência na Universidade de Köln. E suas atividades profissionais, ele as iniciou, como docente - e diretor do Instituto de Geografia - em 1926 na Universidade de Kiel e desde 1929 na Universidade de Bonn. Embora a geografia física recebesse suas primeiras atenções, a contribuição que daria para a geografia humana, especialmente, para a geografia econômica, acabaria ganhando grande evidência. E o que aqui é de importância: o seu objeto privilegiado de estudos viria a ser a geografia dos trópicos. Em face da realidade política vivida pela Alemanha na época, Leo Waibel (como também aconteceria com inúmeros outros pesquisadores daquele país) foi demitido em julho de 1937 e proibido de exercer quaisquer funções em universidades alemãs. Por isso, em 1939 transferiu-se para os Estados Unidos. Mas, em 1946 mudaria para o Brasil, onde permaneceria até 1950. É a passagem de Waibel pelo país nesse período que será examinada nas páginas do presente artigo, destacando-se sua contribuição para o início das relações científicas entre o Brasil e a Alemanha no campo da geografia.
\end{abstract}

Palavras-chave | Alemanha; Brasil; geografia; Leo Waibel.

Código JEL | A18; N90; O18.

\section{THE IMPORTANCE OF LEO WAIBEL TO THE BRAZILIAN GEOGRAPHY AND THE BEGINNING OF SCIENTIFIC RELATIONS BETWEEN BRAZIL AND GERMANY IN THE FIELD OF GEOGRAPHY}

\begin{abstract}
The topic of this article concerns with the importance of the German geographer Leo Waibel for Brazilian geography. Born at the end of the century XIX, Waibel had a singular academic career. He obtained his $\mathrm{PhD}$ title under the guidance of Alfred Hettner at the prestigious University of Heidelberg, and his Habilitation at the University of Köln. He started his
\end{abstract}


professional activities as professor - and director of the Institute of Geography - in 1926 at the University of Kiel and since 1929 at the University of Bonn. Although physical geography received his first attention, the contribution he would give to human geography, especially to economic geography, would gain wide evidence. And what is of importance here: his privileged object of study would be the geography of tropics. In the face of political reality experienced by Germany at the time, Leo Waibel (as also happened with many other researchers in that country) was fired in July 1937 and banned from performing any functions at German universities. So in 1939 he moved to the United States. But in 1946 he moved to Brazil, where he remained until 1950. It is the passage of Waibel through the country at that period that will be examined in the pages of this article, highlighting his contributions to the beginning of the scientific relations between Brazil and Germany in the field of geography.

Keywords | Brazil; geography; Germany; Leo Waibel.

JEL-Code | A18; N90; O18.

\section{LA IMPORTANCIA DE LEO WAIBEL PARA LA GEOGRAFÍA BRASILEÑA Y EL INICIO DE LAS RELACIONES CIENTÍFICAS ENTRE BRASIL Y ALEMANIA EN EL ÁMBITO DE LA GEOGRAFÍA}

\section{Resumen}

El tema de este artículo es la importancia del geógrafo alemán Leo Waibel para la geografía brasileña. Nacido a fines del siglo pasado, Waibel tuvo una carrera académica singular. Hizo su doctorado bajo la orientación de Alfred Hettner, en la prestigiosa Universidad de Heidelberg. Obtuvo su Habilitación en la Universidad de Colonia. Y sus actividades profesionales, Waibel las ha comenzado, como maestro - y director del Instituto de Geografía - en 1926 en la Universidad de Kiel y desde 1929 en la Universidad de Bonn. Aunque la geografía física recibió su primera atención, la contribución que daría a la geografía humana, especialmente la geografía económica, tendría grande evidencia. Y lo que es de importancia aquí: su objeto privilegiado de estudio sería la geografía de los trópicos. Teniendo en cuenta la realidad política vivida por Alemania en ese momento, Leo Waibel (como también sucedió con muchos otros investigadores de aquel país) fue expulsado en julio de 1937 y se le prohibió de realizar cualquier función en universidades alemanas. Así, en 1939 se trasladó a los Estados Unidos. Pero en 1946 se trasladaría a Brasil, donde permanecería hasta 1950. Es el pasaje de Waibel por Brasil en este período que será examinada en las páginas de este artículo, destacando su contribución para el comienzo de las relaciones científicas entre Brasil y Alemania en el campo de la geografía.

Palabras-clave | Alemania; Brasil; geografía; Leo Waibel.

Código JEL | A18; N90; O18.

\section{Introdução}

Leo Waibel (1888-1951) obteve o título de Doutor pela Universidade de Heidelberg, com uma tese biogeográfica, sob a orientação do mais conhecido geógrafo alemão, Alfred Hettner. Já em 1911-1912 familiarizou-se com os trópicos, quando participou de uma expedição ao Kamerun - então colônia alemã, 
atual República dos Camarões -, como assistente de Franz Thorbecke, discípulo de Hettner. Por ocasião de outra viagem de pesquisas à África, em 1914, mais precisamente à colônia alemã Sudoeste da África (hoje Namíbia), foi envolvido em distúrbios causados pelos conflitos entre os poderes coloniais na I Guerra Mundial, mas, não obstante, pôde continuar suas pesquisas naquela região até 1919.

Depois de retornar à Alemanha, formou-se livre docente na Universidade de Colônia e foi nomeado professor e Diretor do Instituto de Geografia, na Universidade de Kiel. Em 1929, mudou de Kiel para Bonn, onde pôde ampliar o Instituto, tornando-o um dos centros de pesquisas geográficas e de ensino mais importantes da Alemanha. Depois de se dedicar às pesquisas biogeográficas, climatológicas, geomorfológicas e temas de geografia humana em Kiel e Bonn, Waibel deu atenção cada vez maior à geografia econômica, que passava por rápido desenvolvimento (PFEIFER; KOHLHEPP, 1984, p. 118-123; bibliografia de Waibel). Durante uma viagem de pesquisas ao México, os conceitos de "paisagem econômica", "formas econômicas" e "formações econômicas" receberam cunho de maior significado pela primeira vez e foram posteriormente desenvolvidos (PFEIFER, 1952a). Já nos anos 1930, além de ter se tornado um dos geógrafos alemães de maior renome, Leo Waibel era internacionalmente considerado uma das grandes personalidades no âmbito da pesquisa (BERNARDES, 1952).

Depois de concluída a monografia "As regiões de matérias-primas da África tropical", redigida no âmbito do seu maior projeto sobre a importância dos trópicos na economia e no comércio mundial, Waibel planejou um segundo volume que seria dedicado à América tropical, principalmente ao Brasil, como o país tropical mais importante. Para tal, Waibel solicitou, em janeiro de 1937, permissão ao Ministério para realizar viagem de pesquisas ao Brasil para o estudo sobre "colonização de agricultores europeus". A tomada de poder pelos nacionais-socialistas na Alemanha e as leis racistas do ano de 1935 dificultaram a situação de Waibel como titular da cátedra de geografia em Bonn, sobretudo pela sua posição crítica em relação ao regime. Waibel estava sendo ameaçado de demissão, pois sua esposa era judia.

Com a obtenção da autorização pelo Ministério para a planejada viagem em 29 de junho de 1937, e a concessão pelo Reitor da Universidade de Bonn, Waibel teve a

\footnotetext{
${ }^{1}$ Waibel (1937). N.A.: as cartas aqui citadas, bem como os relatórios de viagem e os diários de Leo Waibel, salvo menção especial, foram cedidos por Gottfried Pfeifer ao autor, encontrandose em seu arquivo particular em Tübingen.

2 Böhm (1991, p. 234-235); segundo documentos da Faculdade de Matemática e Ciências Naturais (MCN) ref. L. Waibel, 24.01.1937; arquivo da Faculdade de MCN, Universidade de Bonn.
} 
esperança de que a decisão sobre a sua destituição do cargo tivesse sido revogada ${ }^{3}$. Isto infelizmente não aconteceu e Waibel recebeu a notícia oficial da sua demissão em 14 de julho de $1937^{4}$ e, por consequência, a proibição de exercer sua profissão em universidades alemãs.

Interessante verificar que o geógrafo alemão Oskar Schmieder também planejara uma viagem de pesquisa ao Brasil juntamente com um time multidisciplinar, nos anos 1936/37, para realizar pesquisas nas regiões de povoamento de descendentes de alemães no Espírito Santo. Esta tentativa também não foi exitosa, devido à falta de divisas para viagens ao Brasil (SCHMIEDER, 1972, p. 174-175) ${ }^{5}$.

Depois da sua demissão, Waibel decidiu aceitar um convite particular de viagem de pesquisas ao sul do México, à Guatemala e à Costa Rica ${ }^{6}$, de outubro de 1937 a março de 1938. Retornando à Alemanha, aceitou convite de Karl J. Pelzer, um dos seus ex-alunos, para viajar aos Estados Unidos.

Chegou a Nova Iorque em março de 1939, portando a passagem de retorno e, devido a II Guerra Mundial, sua esposa pôde deixar a Alemanha somente em 1940, em uma viagem via Itália. Waibel foi nomeado Research Associate (1939-1941) por intervenção de Isaiah Bowman, que detinha funções de destaque na geografia norte-americana e internacional ${ }^{7}$ e era Presidente da Universidade Johns Hopkins, em Baltimore, desde 1935. Bowman atuava como consultor especial do presidente estadunidense Franklin D. Roosevelt ${ }^{8}$ e coordenava abrangente projeto por incubência dele. O projeto propunha o estudo sobre as possibilidades (e elencava sugestões de áreas apropriadas) de aldeamento no mundo inteiro, excetuando o

\footnotetext{
${ }^{3}$ Nesse processo, o perito em assuntos de geografia do Ministério de Ciências - o colega Wolfgang Panzer, convicto funcionário do partido nazista NSDAP - desempenhou papel especialmente infame. Na reunião decisória da faculdade, em 31 de maio de 1937, somente G. Pfeifer e H. Cloos defenderam Waibel. Vide Böhm (1991, p. 232 ff.) (Documentos do Ministério da Cultura da Prússia, W1D, X 72-1, Microfilme Arquivo Estatal Principal Düsseldorf, NW 5 Bonn 574, 1919-1936, Fl. 291 e 321 e documentos da Faculdade de MCN, ref. L. Waibel, 31.05.1937, Arquivo da Faculdade de MCN, Universidade de Bonn).

${ }^{4}$ Cartas de Waibel para Pfeifer, 07, 13 e 15 de julho de 1937.

${ }^{5}$ Como havia divisas, mesmo que limitadas, para viagens à Argentina e ao Paraguai, Schmieder mudou seus planos e realizou viagem de pesquisa àqueles países juntamente com Herbert Wilhelmy.

${ }^{6}$ O décimo segundo relatório de viagem à Costa Rica, datado de 14 de março de 1938, contendo reconhecimentos sobre o princípio de von Thünen, foi reproduzido em extratos em Pfeifer (1971, p. 114-119). Os resultados dessas viagens foram publicados, em parte, na The Geographical Review (entre outros, WAIBEL, 1939) e na Revista Brasileira de Geografia. Cópias das 13 cartas detalhadas sobre a viagem (118 pp.) encontram-se no arquivo particular do autor.

${ }^{7}$ Direção da American Geographical Society 1915-35; Presidente da Association of American Geographers 1931-33; e Presidente da International Geographical Union (IGU) 1931-34.

${ }^{8}$ Roosevelt estava muito bem impressionado com as publicações de Bowman: "The pioneer fringe" (New York, 1931) e "Limits of land settlement" (New York, 1937); vide Martin (1980, p. 123 ff.).
} 
território dos Estados Unidos, para imigrantes judeus e para a esperada onda de refugiados europeus depois da guerra.

O "Project M" (Migration), do qual Pelzer também participou, estava sujeito a sigilo por motivos de política nacional e externa (MARTIN, 1980, p. 135). A Waibel foi então atribuída a região da América Central. Com base na literatura disponível e conhecimentos locais do pesquisador ${ }^{9}$, resultou em uma identificação geográfica dos países e das regiões ainda não habitadas e de áreas apropriadas para o povoamento de imigrantes europeus. Esta tarefa refletiu-se mais tarde nas pesquisas de Waibel no sul do Brasil e no Espírito Santo. Desses estudos resultaram também publicações sobre a Guatemala, El Salvador, Honduras, Nicarágua, Costa Rica, Panamá e México (Estados de Chihuahua e Durango), bem como uma série de mapas 1:1 milhão (WAIBEL, 1946) ${ }^{10}$. O "Project M", para o qual ele trabalhou de junho de 1944 até junho de 1946, terminou com a morte do Presidente Roosevelt em 1945. Os resultados ficaram sem utilidade e permaneceram trancados na American Geographical Society até $1975^{11}$.

A partir de setembro de 1941, Waibel lecionou na Universidade de Madison, no estado de Wisconsin, em que assumiu, até maio de 1944, o lugar do colega Richard Hartshorne, que havia sido convocado a cumprir serviços militares. Waibel ficou desiludido com a qualidade do ensino geográfico nas universidades americanas ${ }^{12}$, assim como Bowman ${ }^{13}$. Mesmo tendo adquirido a cidadania americana em maio de 1945, ele não conseguiu uma vaga no quadro de efetivos numa universidade do país e, consequentemente, a garantia de aposentadoria, sobretudo devido ao não esclarecimento de sua situação na Alemanha. Caso se efetivasse em uma universidade, ele poderia ter continuado suas pesquisas ${ }^{14}$.

\footnotetext{
${ }^{9}$ No caso de Waibel, vide nota 6.

${ }^{10}$ Estes materiais e os mapas elaborados de cada país foram doados por Waibel à American Geographical Society em New York (WAIBEL, 1946). No Instituto Geográfico da Universidade de Heidelberg havia, em 1964, cópias desse material sem os nomes dos autores. Os volumes foram consultados pelo autor.

${ }^{11}$ Martin (1980, p. 137).

${ }^{12}$ Carta de Waibel a Pfeifer, de 10.10.1947, do Rio de Janeiro, na qual Waibel dizia que Pfeifer "havia superestimado imensamente" o nível delas.

${ }^{13}$ Carta de Bowman para Waibel, de 05.02.1945 (apud MARTIN, 1980, p. 201). Bowman estava preocupado com o fato de os jovens geógrafos nos Estados Unidos não lerem o suficiente e que a geografia "would ... lose standing".

${ }^{14}$ Carta de Waibel a Pfeifer, de 26.12.1946, do Rio de Janeiro: "Nos Estados Unidos eu era 'a failure”". Waibel encontrou em Carl O. Sauer um dos colegas norte-americanos de reputação mais alta, num dos Institutos de Geografia mais conhecidos dos Estados Unidos, a Universidade de California, em Berkeley, onde geógrafos alemães lecionaram antes da guerra (Albrecht Penck, Oskar Schmieder, Gottfried Pfeifer, Wolfgang Panzer, Karl J. Pelzer) e depois da guerra (Fritz Bartz, Herbert Wilhelmy, Gottfried Pfeifer e o autor). Com Carl O. Sauer muito estimado por Pfeifer (1965, entre outros) - Waibel não mais encontrou contatos
} 
Mas Waibel ficou muito contente com a mudança repentina em sua carreira científica, com a qual ele não contava. Em Madison encontravam-se alguns jovens geógrafos brasileiros com bolsas de estudos para cursos de pós-graduação e que eram ouvintes dos seus cursos, como Fábio de Macedo Soares Guimarães e Orlando Valverde ${ }^{15}$, entre outros, que lhe transmitiram um convite oficial do Conselho Nacional de Geografia (CNG) no Rio de Janeiro para desempenhar a tarefa de consultor científico daquela instituição e, consequentemente, do governo brasileiro.

Como ele já pensava no Brasil como a região apropriada para suas pesquisas e como objeto de estudo da planejada "Geografia dos trópicos", ele aceitou a oportunidade com entusiasmo. Neste momento, sua cidadania americana foi de grande utilidade, pois logo depois do final da guerra ele - na condição de cientista alemão - não teria podido assumir um cargo de consultor do governo brasileiro (a entrada do Brasil na II Guerra ao lado dos aliados data de agosto de 1942) ${ }^{16}$.

\section{Fase pioneira da geografia brasileira}

Na chegada de Waibel ao Rio de Janeiro, em 1946, a geografia como ciência no Brasil ainda encontrava-se em fase pioneira e era muito influenciada por geógrafos franceses. Em julho de 1933, Emmanuel de Martonne, na função de Secretário Geral da International Geographical Union (IGU), sugeriu ao Brasil a fundação de um comité nacional e a associação do país ao IGU.

Em 1934 foi fundada a Universidade de São Paulo, contando com grande participação de cientistas franceses. Na Faculdade de Filosofia, Ciências e Letras fora instituída a cátedra de geografia, para a qual Pierre Deffontaines ${ }^{17}$ foi nomeado. Quando ele foi transferido para a Universidade do Brasil ${ }^{18}$ (1935-38), na então capital Rio de Janeiro, foi substituído na USP por Pierre Monbeig ${ }^{19}$, um

adequados, nem no seu campo de trabalho, nem em nível pessoal. Vide Carta referida na nota $\mathrm{n}^{\circ} 12$.

${ }^{15}$ Mais tarde, Fábio de Macedo Soares Guimarães tornou-se diretor do Departamento de Geografia do CNG. Orlando Valverde, que trabalhava estreitamente com Waibel, conduziu posteriormente diversos departamentos do CNG e absorveu os métodos científicos de Waibel, tornando-se o representante e propagador mais enfático da geografia alemã no Brasil (KOHLHEPP, 1991).

${ }^{16}$ Carta de Waibel a Pfeifer, de 26.12.1946, do Rio de Janeiro: "Por enquanto, tudo que é alemão não é bem visto aqui".

${ }^{17}$ Deffontaines (1939, entre outros).

${ }^{18}$ Desde 1935, Universidade do Distrito Federal.

${ }^{19}$ Monbeig ocupou em São Paulo de 1935 a 1937 a cátedra de Geografia e - depois da separação de disciplinas geográficas e da nomeação de colegas brasileiros da área de geografia 
jovem geógrafo que dirigiu, de 1936 a 1946, a Associação dos Geógrafos Brasileiros (fundada por Deffontaines). Durante a estada de Waibel, essa associação tornou-se uma instituição paulistana e transformou-se em associação de nível federal somente em 1945.

Antes da institucionalização da geografia como ciência de nível universitário, alguns intelectuais interessados na geografia científica ocupavam-se como autodidatas em Institutos Histórico-Geográficos nos seus estados ou na Sociedade de Geografia, no Rio de Janeiro. Somente mais tarde geógrafos que viviam longe dos centros de São Paulo e Rio de Janeiro, como Josué de Castro ou Manoel Correia de Andrade, no Nordeste, puderam alcançar destaque.

Com relação às dificuldades ligadas à fundação de um comité nacional brasileiro na IGU, a Academia Brasileira de Ciências havia sugerido fundar uma organização estatal. Com a ajuda da AGB surgiu então o Conselho Nacional de Geografia (CNG) em 1937, como parte do Instituto Nacional de Estatística que, a partir de 1938, tornou-se o Instituto Brasileiro de Geografia e Estatística (IBGE) ${ }^{20}$.

Como parte do IBGE, o CNG era submetido diretamente ao Governo Federal e tinha a incumbência da pesquisa geográfica e do levantamento cartográfico do território brasileiro e da promoção e coordenação das atividades geográficas no país, assim como a ligação à $\mathrm{IGU}^{21}$. Um significado central tinha o CNG como órgão de consultoria e elaboração de fundamentos especializados para o apoio nas decisões de governo e outras instituições estatais.

Nesta situação de advento da geografia, como também do desenvolvimento econômico no Brasil depois da II Guerra Mundial, Waibel iniciou suas atividades como consultor científico com o estatuto de professor universitário no CNG, Rio de Janeiro, sem a necessidade do compromisso com o ensino:

Minha tarefa é o exame sistemático dos "pioneer belts" do Brasil. De certa forma, eu tenho um marco histórico a cumprir: eu devo mostrar à administração que a geografia não é somente uma disciplina acadêmica, mas que ela também possui grande significado prático para o planejamento regional, possibilidades de colonização etc. ${ }^{22}$

\footnotetext{
física e regional - de 1938 a 1946 a cátedra de Geografia Humana, obtendo grande influência, principalmente, em São Paulo (MONBEIG, 1940; 1952; 1991; e THÉRY; DROULERS, 1991).

${ }^{20}$ CNG (1939); Sternberg (1951).

${ }^{21}$ O CNG publicou as duas primeiras revistas geográficas no Brasil: Revista Brasileira de Geografia (desde 1939) e o Boletim Geográfico (desde 1943).

${ }^{22}$ Carta de Waibel a Pfeifer, de 26.12.1946, do Rio de Janeiro.
} 
Waibel chegou a um país onde geógrafos franceses haviam dado o arranque. Sua chegada - pouco depois do fim da guerra - não contou com a aprovação de todos:

Os geógrafos americanos e franceses não apreciam o fato de um alemão ter uma incumbência de tamanha importância e, se eu não fosse naturalizado americano, eu já teria sido afastado e nem sequer teria recebido o convite para trabalhar aqui por uns anos. ${ }^{23}$

Havia poucos trabalhos científicos fundamentados sobre a geografia do Brasil. Bem cedo, Pierre Denis (1909) elaborou um panorama geográfico do Brasil. Um dos primeiros representantes dos geógrafos brasileiros foi Delgado de Carvalho (1913), com a "Geografia do Brasil", de sua autoria. Distinguiram-se o norteamericano Preston E. James $(1932,1938)$, com pesquisas de campo no Brasil e o suíço Heinrich Gutersohn (1940), com um estudo sobre São Paulo, entre outros. Além dos já citados Deffontaines e Monbeig, Francis Ruellan, outro colega francês, lecionou geomorfologia na Universidade do Rio de Janeiro (1941-52).

Excetuando alguns relatórios esporádicos durante curtas estadas, somente poucos pesquisadores realizaram trabalho fundamentado sobre o Brasil no âmbito da geografia científica na Alemanha: Woldemar Schultz (1865) ${ }^{24}$, Johann Wappäus (1871), Alfred Hettner (1891), Ernst Wagemann (1915), Bernhard Brandt (1922), Oskar Schmieder (1929, 1932) ${ }^{25}$ ou Reinhard Maack (entre outros, 1937) ${ }^{26}$ e, especialmente, Otto Maull (1930a, b), depois de uma longa viagem de pesquisas em $1923^{27}$.

Leo Waibel foi o primeiro geógrafo alemão que, como os colegas franceses, trabalhou durante um período mais longo no Brasil (1946-1950). Seu trabalho

\footnotetext{
${ }^{23}$ Carta de Waibel para Alfred Philippson, de 12.01.1947. Em Böhm (1991, p. 420, doc. 41); segundo documentos da Faculdade de Matemática e Ciências Naturais, ref. L.Waibel, Arquivo da Faculdade, Universidade de Bonn.

${ }^{24}$ Vide KOHLHEPP, G. Woldemar Schultz: Ein Pionier geographischer Forschung in Brasilien (um pioneiro da pesquisa geográfica no Brasil). Geographische Zeitschrift, 56 (3), p. 225-228, 1968.

${ }^{25}$ Com base em curta estada e avaliação da literatura científica.

${ }^{26}$ Maack, que viveu no Brasil a partir de 1923, publicou diversos trabalhos sobre geografia física e geologia; vide KOHLHEPP, G. Das geographische Lebenswerk von Reinhard Maack (a obra geográfica de Reinhard Maack). Geographische Zeitschrift, 59 (3), p. 165-176, 1971.

${ }^{27}$ Das poucas teses alemãs de geografia sobre temas brasileiros elaboradas naquele período, há o trabalho na Universidade de Tübingen, de ENDRESS, S. Blumenau: Werden und Wesen einer deutsch-brasilianischen Landschaft (Blumenau: evolução e estrutura de uma paisagem teutobrasileira) (= Schriften des Deutschen Auslands-Instituts, N. R., N. 5), Stuttgart: Öhringen, 1938 - elaborada depois de estada mais longa no local.
} 
concentrou-se em viagens a determinadas regiões e à elaboração científica dos resultados. Ele podia se dedicar inteiramente à pesquisa científica. Ao contrário dos geógrafos franceses, ele não estava ligado a uma universidade, isto é, não se ocupava das tarefas de ensino e administração. As vantagens de ter mais tempo para a pesquisa mostrou-se, mais tarde, desvantagem para o desenvolvimento da geografia no Brasil, pois Waibel não participou da formação universitária da geração seguinte de geógrafos. Seu grupo de assistentes era relativamente pequeno. Assim, seus pensamentos metodológicos não puderam estar à disposição de um grupo maior de estudantes. Mas, por meio de suas publicações e dos colaboradores que traduziram seus trabalhos para o português, suas ideias tiveram grande ressonância no Brasil, apesar dos obstáculos linguísticos (VALVERDE, 1971a; BERNARDES, 1952, 1983).

$\mathrm{Na}$ fase inicial da geografia brasileira deu-se uma situação de concorrência entre os geógrafos das metrópoles Rio de Janeiro e São Paulo - tradicionalmente já havia preconceitos entre as duas metrópoles. Além disso, as universidades locais estavam fortemente influenciadas por geógrafos estrangeiros que tentavam formar, com êxito, "escolas" em suas respectivas universidades. A forte presença de cientistas estrangeiros, principalmente em São Paulo, levou, no inicio, a críticas de círculos nacionalistas contra a contratação de tantos estrangeiros (MONBEIG, 1991).

A posição inicial de liderança da geografia em São Paulo equilibrou-se com a instituição do CNG na capital Rio de Janeiro e, mais tarde, pelo desenvolvimento do Centro de Pesquisas de Geografia do Brasil (fundado em 1952) no Rio de Janeiro, sob a direção de Hilgard O’Reilly Sternberg, que também foi VicePresidente da IGU (de 1952 a 1960) e Secretário Executivo do Comité Nacional e do Comité de Organização do $18^{\circ}$ Congresso Internacional de Geografia, em 1956, no Rio de Janeiro.

O CNG tinha a função e a posição de realizar excursões, oferecer oportunidades de pesquisas e financiar publicações com meios estatais, o que provocou tensões com a geografia universitária que se via confrontada com grandes dificuldades financeiras e organizacionais. Por outro lado, o CNG estava sujeito à dependência estatal nas suas funções de chefia, o que, no entanto, não teve efeitos negativos nem no campo pessoal nem de conteúdo. Waibel levou métodos da geografia humana alemã ao Rio de Janeiro, justamente na época do pós-guerra, quando havia preconceitos contra seus representantes, mais por motivos políticos do que por motivos científicos. 


\section{O resultado científico das pesquisas de Leo Waibel no Brasil}

Quando Waibel iniciou seus trabalhos no Brasil, o CNG tinha o objetivo de elaborar um levantamento da diferenciação geográfica regional do Brasil. No entanto, Waibel reconheceu imediatamente que a condição para a pesquisa fundamentada na geografia regional é a longa familiaridade com a região a ser pesquisada. Por isso, dentre os inúmeros temas do CNG, Waibel escolheu temas da geografia geral (WAIBEL, 1950/1984) ${ }^{28}$, representados em dois setores da geografia agrária e de povoamento: o uso da terra e a colonização agrária.

Foram elaborados, sobretudo, diversos sistemas de uso da terra. A colonização agrária não compreendia somente duas grandes regiões - o Planalto Central e as regiões de povoamento europeu no sul do Brasil, mas tratava também do questionamento de um dogma do uso da terra no Brasil: as possibilidades da agricultura somente eram consideradas em regiões de mata, enquanto que os Campos cerrados do Planalto Central e os campos limpos no sul do Brasil eram usados somente para pasto bovino.

Como um dos primeiros geógrafos, Waibel dedicou-se aos estudos da agricultura dos pequenos colonos - em todas as suas facetas -, uma temática que até então ninguém havia se ocupado cientificamente no Brasil e que não contava com apoio da política agrária. Waibel dedicava especial atenção à expansão das fronteiras da colonização, um fenômeno tradicional no Brasil desde os tempos coloniais e à caracterização das zonas pioneiras existentes no país.

Finalmente, Waibel foi confrontado com uma oportunidade única para um geógrafo naquela época, ou seja, um tema relevante de planejamento na geografia aplicada, que era a procura de localização apropriada para a nova capital do Brasil no Planalto Central.

A primeira viagem de informação ao Planalto Central, em julho e agosto de 1946, serviu ao estudo da distribuição da vegetação natural e às mudanças antrópicas (WAIBEL, 1947a) $^{29}$. Ele teria querido iniciar suas investigações em Mato Grosso para conhecer melhor uma região cuja paisagem natural ainda não tinha sido afetada pela colonização e pela consequente "marcha para o oeste". No entanto, a parte central deste Estado ainda não podia ser alcançada por via terrestre. Na parte sul de Goiás surgiu um novo impulso de colonização depois de primeiras abordagens no século XVIII. No chamado Mato Grosso de Goiás, região de mata,

\footnotetext{
${ }^{28}$ A citação das publicações de Waibel aparece de acordo com o ano da primeira publicação no Brasil, assim como o da publicação da tradução alemã em Pfeifer; Kohlhepp (1984). Textos citados ao pé da letra seguem a versão em idioma alemão.

${ }^{29}$ A viagem foi realizada por via férrea até Anápolis (Goiás), cidade que, desde 1935, era o ponto final da ligação ferroviária localizada no extremo interior.
} 
formou-se a primeira zona pioneira chamada "Colônia Agrícola Nacional" e ao sul de Anápolis foi fundada a capital de Goiás, Goiânia, em 1937.

O interesse de Waibel pela difusão da mata e do campo e, com isso, pelas condições para o planejamento da colonização agrária, levaram à necessidade de elaboração de um novo mapa da vegetação brasileira (WAIBEL, 1948c). Para tal foram utilizadas imagens aéreas feitas durante a guerra pelas forças armadas americanas. Os trabalhos cartográficos preliminares foram recolhidos no CNG, que coordenou a elaboração do mapa da vegetação.

A questão da procura do local ideal para a construção da capital nacional, muito controversa e intensamente debatida no Brasil, tem uma longa história ${ }^{30}$. No ano de 1946 foi finalmente formada a Comissão de Estudos para a Localização da Nova Capital do Brasil, sob o comando do General Polli Coelho, e era composta por mais doze membros. Foram escolhidas oito regiões parciais no Planalto Central para um exame especial - quatro no ocidente de Minas Gerais (Triângulo Mineiro) e quatro ao sul e no centro de Goiás ${ }^{31}$.

Para Waibel e seu grupo de trabalho no CNG, o assunto passou a ser um grande desafio no que se refere à pesquisa geográfica aplicada, além de ser uma prova de fogo para a recém-criada disciplina "geografia" no Brasil, cujo significado foi muitas vezes minimizado por concorrentes de outras ciências. Em 1947, duas expedições geográficas receberam a incumbência de procurar o local de instalação da capital: uma com Francis Ruellan, geomorfólogo francês que liderou a primeira expedição com um grupo de estudantes, e o segundo grupo, do CNG, tendo à frente Guimarães, Waibel e mais quatro pessoas com formação geográfica, que realizou trabalho de campo minucioso durante três meses ${ }^{32}$.

Enquanto que para Ruellan a localização da nova capital era o mais importante, o grupo de Waibel, no entanto, tentou juntar à análise da situação geográfica critérios da geografia econômica como, por exemplo, possibilidades de plantio para abastecimento ${ }^{33}$, distâncias de mercados etc ${ }^{34}$. Em 1948 foram apresentados

\footnotetext{
${ }^{30}$ No âmbito do deslocamento do centro de interesse econômico, a capital da Colônia Brasileira foi transferida, em 1763, de São Salvador da Bahia, no nordeste, para o Rio de Janeiro, no sudeste do país. Desde o tempo colonial discutia-se sobre a fundação da capital no "centro" do Brasil. Em 1892, a expedição Cruls explorou, juntamente com um grupo de peritos em ciências naturais, o planalto em Goiás, apresentando em 1894 um abrangente relatório, depositado e "esquecido" nos arquivos do governo por quase 50 anos; vide Pfeifer (1962).

${ }^{31}$ Mapa em Pfeifer (1962, p. 293).

${ }^{32}$ Para tal foram rodados cerca de oito mil quilômetros (WAIBEL, 1947a; 1947b).

${ }^{33} \mathrm{O}$ trabalho de Waibel sobre a Lei de von Thünen e sua aplicação na Costa Rica (WAIBEL, 1948b), reproduzido em CNG (1958), foi baseado em um dos seus trabalhos mais antigos sobre a diferenciação geográfica-econômica do México (1929) e em "Problemas da geografia agrária" (1933), como seus trabalhos de campo na Costa Rica em 1939 [12 relatório de viagem em Pfeifer (1971); vide nota de rodapé 6].
} 
os resultados ainda sigilosos das expedições à Comissão Coelho, que mantinha o poder de decisão para posterior apresentação das respectivas recomendações ao Presidente da República. Neste contexto, sete membros da comissão votaram a favor de uma região em Goiás ("Quadrilátero Cruls") e cinco membros votaram a favor de uma região no Triângulo Mineiro. O grupo de Waibel havia dado prioridade a uma das regiões escolhidas na última área, enquanto que a região escolhida com pequena maioria havia sido citada por Waibel somente em sexto lugar.

Quando o relatório final da Comissão Coelho foi publicado, os prós e contras da recomendação foram largamente debatidos no Brasil. Uma observação polêmica do General Polli Coelho contra sua pessoa levou Waibel a uma forte réplica no "O Jornal", do Rio de Janeiro. Como o CNG não podia publicar oficialmente o artigo de Waibel por ser uma instituição estatal, a matéria surgiu numa revista do CNG (WAIBEL, 1948d) ${ }^{35}$ somente em 1961, depois do falecimento de todos os envolvidos na questão.

Waibel defendeu-se veementemente contra a repreensão de que o conteúdo do relatório do $\mathrm{CNG}$ continha somente determinismos geográficos sem considerar o nível geopolítico do problema - e justamente o contrário correspondeu à realidade. Em sua defesa, Waibel criticou os argumentos da repreensão sem fundamento, a desconsideração dos seus métodos científicos e o desconhecimento do General em relação à literatura especializada e da terminologia da geografia e da geografia política (beartland, core area etc.).

Waibel esclareceu, detalhadamente, os métodos da geografia alemã e francesa, assim como as diferenças entre Ratzel e Hettner, e chamou a geopolítica - depois do episódio do General Karl Haushofer na Alemanha nazista - de "pseudociência", de qual seu adversário seria um fervoroso adepto. A menção do General Coelho a uma palestra de Maull no ano de 1923 no Rio de Janeiro (com base em uma publicação posterior - Maull, 1930b) mostrou que os termos Brasil Central e Brasil do "Meio-Centro", o último uma definição de Maull, localizado entre as latitudes de $17^{\circ}$ e $24^{\circ}$ sul, foi trocado pelo chefe da comissão ou interpretado de forma errônea.

A conclusão de Waibel foi "[...] que a nova capital do Brasil deveria estar localizada dentro da região econômica da core area do país e não no centro geométrico" (WAIBEL, 1948d/1961, p. 617). O Triângulo Mineiro, local favorecido por Waibel, era certamente apropriado, no entanto, Waibel havia

\footnotetext{
${ }^{34}$ Vide Guimarães (1949), que incluiu os resultados da expedição e as reflexões teóricas de Waibel.

${ }^{35}$ Artigo "Contribuição ao problema da mudança da capital", de 19.12.1948, em "O Jornal" (Rio de Janeiro), reproduzido em Boletim Geográfico 19 (164), 1961, p. 612-617 sob "Determinismo geográfico e geopolítico".
} 
subestimado o significado geoestratégico de Brasília para o desenvolvimento do país como também os interesses pessoais dos atores políticos daquela época.

Waibel salientou que, como estrangeiro, não teria se envolvido no debate da escolha do local para a capital, e justificou seu envolvimento lembrando o seu mandato oficial para pesquisa e a sua qualificação como geógrafo, anteriormente contestada. Teria sido melhor publicar o conteúdo do artigo em uma revista especializada e não em um jornal - ato corajoso tanto do autor como da editora -, mas era a única oportunidade para uma reação pública. Esta forma de contradição a um alto representante militar logo depois do final da guerra foi uma reação incomum e arriscada, mesmo que o protesto tenha sido assinado por Waibel como cidadão naturalizado americano.

Depois da morte de Waibel, em 1953, foi iniciado o processo adicional de escolha da capital. Para tal foram examinadas detalhadamente cinco regiões entre o 15³0' e $17^{\circ}$ de latitude sul na região "Quadrilátero Cruls", sem consideração a argumentos geográficos. Em 1955 foi, finalmente, acertado o Distrito Federal com $5.850 \mathrm{~km}^{2}$ e Brasília como o novo nome da capital ${ }^{36}$. A cidade de Brasília foi construída no Planalto Central, a 1.100 metros de altitude sobre o nível do mar, a partir de setembro de 1956, por iniciativa do então novo Presidente da República Juscelino Kubitschek. O "Plano Piloto" foi inaugurado em abril de 1960.

Waibel não mais presenciou a atual Brasília - cidade com mais de um milhão de habitantes, ostentando o famoso plano do urbanista Lucio Costa e todos os highlights arquitetônicos de Oscar Niemeyer. Brasília tornou-se não somente o símbolo do urbanismo moderno do Brasil, mas o símbolo político do governo central. A exploração do interior, que deveria iniciar a nova "marcha para o oeste", deu início à integração da Amazônia no espaço nacional ${ }^{37}$.

$$
* * *
$$

Os trabalhos de Waibel relativos ao uso da terra no Planalto Central semiúmido do Brasil (WAIBEL, 1948a/1984) foram realizados com ajuda de botânicos e continham pesquisas detalhadas da vegetação regional. A impressionante diversidade das formações da vegetação, matas com diversas classificações do sempre verde até semilatifoliada, a predominante área dos Campos cerrados e a vegetação intermediária entre mata e Campo cerrado, o Cerradão, foram descritos

\footnotetext{
${ }^{36}$ Vide, detalhado, Vieira (1959).

${ }^{37}$ Quando foi demarcada a fronteira do Distrito Federal, os insiders próximos ao governo já haviam adquirido grandes áreas de terra por preços mínimos, segundo relatórios da imprensa brasileira; mais tarde foram compradas pelo Estado por um preço exorbitante para a construção da capital. Este aspecto da decisão política sobre a localização da capital não teria sido realizável com métodos científicos.
} 
detalhadamente com a inclusão de referências à qualidade dos solos. Waibel pleiteou pela introdução da expressão "campo cerrado" - um intermediário entre mata menos espessa e vegetação do tipo savana - na geografia de vegetação e era da opinião de que esta era a vegetação climax desta região.

Uma questão básica da pesquisa de Waibel foi o problema ainda não solucionado, na época, da aptidão dos Campos cerrados para o uso da terra. Segundo a sua opinião, não havia lavoura nos Campos cerrados, pois ainda havia matas suficientes. O princípio brasileiro de fixar a lavoura somente em solos de matas e a predominância de criação extensiva do gado nos Campos cerrados refletiu-se nos preços do solo: Os solos dos Campos cerrados eram 50\% mais baratos do que os das matas secas (matas de segunda categoria). Em suas viagens, Waibel constatou que os chapadões - superficies mesozoicas de arenitos, planas e de longo alcance -, de 1.000 até 1.150 metros sobre o nível do mar, solo relativamente pobre, vermelho argilo-arenoso, contavam com um lençol freático favorável de 10 até 20 metros de profundidade e não apontavam marcas de erosão devido à canga. Waibel estava convencido de que "num futuro próximo, os melhores tipos de solo nos Campos cerrados do Planalto Central do Brasil seriam cultivados de forma semelhante às antigas áreas de florestas da Europa Central" ${ }^{\prime 3}$, isto é, por meio de arado, com rotação de culturas e plantas cultivadas mais sofisticadas. Essa avaliação positiva de Waibel quanto às potencialidades do uso da terra nos Campos cerrados foi uma verdadeira sensação na segunda metade dos anos 1940.

Como previsto por Waibel, o desenvolvimento nos Campos cerrados a partir de meados dos anos 1970 sofreu rápida mudança de paradigma devido aos novos métodos na agricultura (mecanização, fertilização do solo, uso de pesticidas etc.) ${ }^{39}$. O plantio de soja modificou totalmente as chapadas excelentemente mecanizadas, diminuindo assim a área para a criação bovina extensiva. A migração de fazendeiros do sul do Brasil para Mato Grosso levou à fundação de novas cidades pioneiras e à mudança da liderança política, antes formada por criadores de gado e hoje por fazendeiros da soja. A periferia integrada através do mercado globalizado, apoiada por programas estatais especiais para a exploração do Planalto Central, viabilizou o desenvolvimento de redes agroindustriais e a criação de um milieu inovador depois da diversificação do uso da terra ${ }^{40}$.

O aumento progressivo da rotação das culturas soja-algodão ou soja-milho fez com que surgissem grandes e médios estabelecimentos agrícolas, altamente mecanizados, que, com a utilização do plantio direto, minimizaram o perigo da

\footnotetext{
${ }^{38}$ Waibel (1948a/1984, p. 28).

${ }^{39}$ Vide nota 101.

${ }^{40}$ Vide, entre outros, Kohlhepp; Blumenschein (1999), Blumenschein (2001) e Coy (2003).
} 
erosão. Nos últimos anos, a plantação da cana-de-açúcar para a produção de etanol $^{41}$ avançou nos Campos cerrados.

Nos anos de 1947 e 1948, Waibel concentrou-se nos trabalhos de campo para os estudos da colonização agrária no sul do Brasil. Os descendentes de alemães, italianos e japoneses, estes últimos no norte do Paraná, colonizaram regiões no sul do Brasil que por muito tempo foram tratadas com desinteresse e desconfiança pelo Governo Federal.

$$
* * *
$$

As atividades propagandistas da organização nazista NSDAP no Brasil mudaram a situação no país na segunda metade dos anos 1930. Na falta de escolas estatais, o governo brasileiro viu-se obrigado a nacionalizar, em 1938, as escolas privadas nas colônias alemãs ${ }^{42}$. $\mathrm{Na}$ ocasião, os idiomas alemão e italiano eram proibidos em escolas e nos atos religiosos. Quando o Brasil aderiu à guerra, em 1942, havia muita apreensão diante da chamada "quinta coluna", isto é, teuto-brasileiros sob a influência da ideologia nazista. O grupo era pequeno, mas ativo, e conduziu a uma reação exagerada, ao descrédito e à perseguição de grande maioria de brasileiros, descendentes de alemães e italianos. Durante a guerra era proibido falar alemão, sob pena de lei, e livros em língua alemã foram incendiados. Nos tempos de guerra, os Estados Unidos temiam exageradamente o efeito de solidarização de brasileiros, descendentes de alemães, especialmente os da população urbana. Na época antes da II Guerra, um grupo de teuto-brasileiros deixou-se levar pelo chamado "Retorno ao Reich". Nos anos pós-guerra puderam retornar ao Brasil.

Logo depois da guerra, os estudos de Waibel nos Estados sulistas do Rio Grande do Sul, Santa Catarina e Paraná foram realizados em ambiente difícil. Waibel pôde se apresentar oficialmente como consultor do $\mathrm{CNG}$, igualmente como americano naturalizado. Nas áreas onde havia grande parte de descendentes de alemães, no entanto, não era vantajoso fazer uso do idioma alemão. Muitos deles, principalmente nas cidades, ainda temiam falar alemão (WAIBEL, 1947b) nos primeiros anos pós-guerra, sobretudo com membros de uma instituição estatal. A população rural, principalmente, as mulheres, quase não falava português. Acresce ainda que nas colônias havia um "sentimento latente de submissão", certamente devido aos déficits linguísticos, diante de luso-brasileiros da área urbana (WILLEMS, 1946, p. 126).

\footnotetext{
${ }^{41}$ Vide Kohlhepp (2013).

${ }^{42}$ Roche (1959).
} 
Afirmações críticas contra repartições não eram de bom tom, em todos os níveis. A cultura teuto-brasileira não mais se recuperou do choque da discriminação existente durante a guerra o que Waibel muito lamentou, entendendo, no entanto, a reação do governo brasileiro em relação às atividades nazistas naquela região, pouco antes do início da guerra ${ }^{43}$.

Depois da guerra, o governo brasileiro reservou-se o direito de privilegiar a imigração de pessoas com "profissões urbanas" e somente em raros casos concedeu a imigração a camponeses. Com isso, tornou-se irrelevante para Waibel a elaboração científica de sugestões de regiões adequadas para a colonização de imigrantes europeus, atividade que exercia nos Estados Unidos, durante a guerra. Como não havia conhecimento aprofundado sobre a situação existente no sul do Brasil, o governo brasileiro priorizou esclarecer a atual situação através de pesquisas do grupo do CNG. Waibel sugeriu então a elaboração de um "Atlas da colonização no Brasil" ${ }^{\prime 4}$.

Em meados dos anos 1940, as viagens de pesquisas geográficas no sul do Brasil não contavam com apoio de contatos científicos. Para Rio de Janeiro e São Paulo, o sul do Brasil estava muito distante e quase não existia intercâmbio científico. Nas universidades mais antigas de Curitiba (onde Waibel contou com o apoio do geólogo e geógrafo Reinhard Maack) e em Porto Alegre, a geografia humana ainda estava na fase inicial. A Universidade Católica de Porto Alegre (PUC) foi instalada entre 1945 e 1948, dando foco às ciências naturais. Em Santa Catarina foi fundada a primeira Universidade Federal (UFSC) no final dos anos 1950, na capital Florianópolis, onde Victor A. Peluso Jr. assumiu a cátedra de geografia em 1962.

Quando Waibel iniciou seu programa de trabalho no sul do Brasil, o tema da colonização das regiões de florestas tropicais e subtropicais por imigrantes alemães, a partir de 1824, e italianos, a partir de 1875, já constava da literatura como modelo bem sucedido de colônias de agricultores da Europa Central e do Sul. Os elogios de visitantes aos descendentes alemães pela alta qualidade do trabalho eram frequentemente ligados à insinuação alemã-nacionalista, embora o trabalho dos colonos tenha sido realmente da mais alta qualidade.

Para Waibel, a realidade do desenvolvimento rural mostrou-se muito mais diferenciada. A análise sistemática dos sistemas agrícolas ${ }^{45}$ anulou praticamente a

\footnotetext{
43 “A situação da cultura alemã no Rio Grande do Sul estava tão desolada como em Santa Catarina; o setor cultural praticamente acabou, e nunca mais poderá se recuperar. Com mais tato teria sido possível construir uma contrapartida (linguística; nota do autor) alemã à parte francesa no Canadá. Isto também foi culpa dos nazistas" (Carta de Waibel a Pfeifer, de 16.03.1948, do Rio de Janeiro).

${ }^{44}$ Carta de Waibel a Pfeifer, de 16.03.1948: “A colonização precisa urgentemente uma interpretação geográfica".

${ }^{45}$ Com relação a esta temática e à contribuição da geografia agrária de Waibel, vide o estudo de Virgínia Etges neste livro, como também em Etges (2000).
} 
avaliação predominante. $\mathrm{Na}$ verdade, o êxito da imigração deveria ser a criação de uma classe média de pequenos agricultores no Brasil entre latifundiários que até 1888 ainda mantinham a escravidão e trabalhadores na agricultura sem terra. $\mathrm{O}$ verdadeiro problema foi o desconhecimento, a despreocupação e a ambição econômica daqueles que eram responsáveis pela planejada colonização agrária, tanto estatal como privada. Waibel (1950/1984, p.107) resumiu esse tema em três pontos, ora complementado pelo autor:

1. Na maioria das vezes, os colonos imigrados não eram agricultores experientes. Eram trabalhadores rurais ou possuíam outra profissão. A colonização transcorria sob grandes dificuldades, sem capital e ajuda local, longe dos mercados urbanos e em completo isolamento cultural. O povoamento rural disperso linear, as casas isoladas dos vizinhos ao longo das picadas, os lotes estreitos ao longo da estrada e do rio, que se estendiam numa longa faixa retangular até o divisor de águas ("Waldhufenflur") contribuiram para essa situação. Acresce ainda que, nas regiões de pequenos agricultores, o cooperativismo sofreu descrédito devido à teimosia e querelas dos envolvidos e, muito frequentemente, por causa de irregularidades na administração financeira.

2. As regiões de colonização atribuídas estavam situadas quase que unicamente em áreas de matas distantes na planície baixa, permitindo somente a agricultura de rotação de terras no sistema de roças, enquanto que o campo aberto, os chamados campos limpos, área de clima apropriado no planalto do sul do Brasil, já estava tomado por grandes fazendas com criação extensiva de gado bovino. Acresce ainda que os criadores de gado faziam parte da elite política da região, sentindo seu poder ameaçado pelos imigrantes e pela agricultura menosprezada dos pequenos agricultores.

3. Os lotes de 20 a 30 hectares dados aos colonos sem recursos eram muito pequenos para o sistema extensivo da rotação de terras - sistema que deixa a fertilidade do solo exaurida pela rotação demasiadamente rápida. Isto não conduzia somente à pobreza, como também à migração de futuras gerações para as novas frentes pioneiras no sul do país, principalmente no caso da preponderante partilha em grandes famílias. Gerações posteriores tiveram que emigrar para o centro do Brasil, para a Amazônia e para o leste do Paraguai.

À emigração alemã ao Brasil que, aliás, estava à sombra da emigração para os Estados Unidos, faltou continuidade desde seu início por causa das restrições do "Rescrito de Heydt" na Prússia, que proibiu, a partir de 1859, o recrutamento para emigração para o Brasil devido a relatórios sobre a exploração de imigrantes no sudeste brasileiro. Esta proibição foi estendida para o Deutsches Reich em $1871^{46}$, que - depois de 1884 - tinha interesse muito maior nas emigrações para as novas colônias alemãs. Finalmente, com o início da I Guerra Mundial, esgotou-se a

\footnotetext{
46 "Rescrito de von der Heyde" na Prússia, dirigido quase que unicamente contra o trabalho nas plantações em São Paulo, anulado oficialmente em 1896.
} 
emigração alemã, não havendo assim novas gerações de agricultores com conhecimentos modernos de agricultura.

Waibel dedicou atenção especial ao exame sistemático dos sistemas agrícolas dos pequenos agricultores no sul do Brasil, o "parente pobre" da agricultura brasileira $^{47}$. Waibel surpreendeu-se ao constatar que ainda predominava o sistema de rotação de terras primitivo no contingente definido de pequenos lotes - ao contrário da agricultura nômade nos trópicos. A agricultura de enxada em barrancos íngremes e em regiões distantes, destinada à produção de gêneros alimentícios básicos como milho, feijão e mandioca na economia de subsistência paralela à criação de suínos era compreensível, mas a rápida rotação das terras, depois de pouco tempo de recuperação do solo na capoeira, levou à exploração excessiva e à destruição do potencial natural.

No Brasil, a chamada economia da roça, que é utilizada mundialmente em regiões de matas $^{48}$, significou a fase final das atividades para milhares de colonos, conduzindo-os não só à pobreza, mas também à decadência social e cultural, à chamada "miséria da mata" e à "caboclização"49. No Espírito Santo, região leste dos trópicos brasileiros, este desenvolvimento foi ainda mais problemático, pois estava frequentemente ligado a doenças infecciosas. Pfeifer (1953) alertou, com razão, ao fato de o mesmo ter acontecido nas colônias agrícolas bem sucedidas nos Estados Unidos, onde havia grupos retrógrados como os poor whites dos Appalaches.

Com a expressão "sistema de rotação de terras melhorada" "50, Waibel tentou descrever a situação quando ainda era usado o sistema de rotação de terras, juntamente com arado, em lotes nos vales. Não se usava esterco. Adubar exige a ligação da lavoura com a criação de gado, o que não existia ou então ocorria de forma insuficiente neste sistema, como também no do plantio de cereais e de batatas. Waibel ressaltou que, ao contrário das formas de economia de Eduard Hahn, o instrumento de trabalho (cavadeira, enxada, arado etc.) não é decisivo, mas sim todo o sistema agrícola junto à adubagem (WAIBEL, 1955a, p. 57).

\footnotetext{
${ }^{47}$ Waibel (1950/1984, p. 110), Waibel (1949/1984) e Waibel (1955a).

${ }^{48}$ Vide Valverde (1971b).

${ }^{49}$ Vide Waibel (1955a, p. 89) e Willems (1946). A redução de colonos europeus "agricultores de arado" para "agricultores de enxada" foi examinada por Wilhelmy (1940), no leste do Paraguai e em Misiones/Argentina, o que já fora analisado por Hettner (1891) no Rio Grande do Sul e descrito por Wagemann (1915) no Espírito Santo. Designações locais como "Jammertal" (Vale da miséria) ou "Hungerschneis" (Picada da fome) são, até hoje, testemunhos dos sérios problemas por que passaram esses colonos.

${ }^{50}$ Roche (1959, p. 235) achou esta expressão injustificada.
} 
Waibel constatou que era necessária uma nova classificação dos sistemas de agricultura, o que ele gostaria de ter pesquisado.

No sistema de rotação de culturas primitiva, a rotação de culturas é apoiada ou na aplicação de esterco natural ou no uso de caros adubos artificiais. Como a criação de animais não está integrada ao sistema, falta nesse caso o valioso estrume animal.

O sistema de rotação de culturas melhorada, quando a agricultura e a criação de gado estão integradas, requer, além de capital para a compra de máquinas e do próprio gado, também conhecimentos específicos sobre agricultura, principalmente, no que se refere à aplicação de esterco. Este sistema, que produz nas proximidades do mercado e sob condições naturais favoráveis, segundo observações de Waibel, estava sendo empregado em apenas $5 \%$ a $10 \%$ dos estabelecimentos no sul do Brasil, sobretudo, por camponeses teuto-brasileiros. Esta percentagem é, seguramente, muito baixa, tendo em vista que Waibel não visitou algumas regiões com vales largos e agricultura de rotação de culturas como, por exemplo, a Baixada de Jacuí, no Rio Grande do Sul, conforme informação extraída dos seus diários. Depois de sua última excursão à Bahia, Waibel pôde verificar que esse tipo de sistema agrícola também era empregado com êxito em outras regiões do Brasil, como, por exemplo, nas áreas de plantio do tabaco no Recôncavo. Ficou comprovado que era possível o emprego do estrume, até então controverso, na planície tropical, sem contar com a mão de obra de colonos europeus ${ }^{51}$.

Para Waibel, a questão central da colonização europeia no sul do Brasil era a "mínima quantidade de terra necessária para proporcionar a um agricultor e sua família um padrão econômico e cultural decente" (WAIBEL, 1949, p. 195) [...] "para lhes garantir uma existência satisfatória no presente e no futuro" (WAIBEL, 1955a, p. 87). Tudo depende naturalmente do sistema agrícola usado e da qualidade do solo.

O cálculo de Waibel quanto ao tamanho de terra agrícola necessário para uma família de 5 a 7 pessoas teria que ser modificado, pois por família e por ano não é possível desmatar mais do que 2 hectares com machado, mas o uso da terra após o desmatamento poderia se dar no transcurso de mais de um ano. Waibel calculou a área agrícola necessária ao sistema de rotação de terras com base em 55 ha (solos bons) e 105 ha (solos ruins). Mas, considerando-se o tempo de 20 anos para a regeneração do solo e 5 hectares de área de plantio em 3 anos de uso, o cálculo deveria ser feito com $40 \mathrm{ha}^{52}$ sem áreas para pastagem e sem considerar a partilha. De qualquer forma, os lotes atribuídos eram quase todos pequenos demais diante das condições existentes.

\footnotetext{
${ }^{51}$ Waibel (1950/1984, p. 113-115).

${ }^{52}$ Vide Lücker (1986, p. 62-63).
} 
No sul do Brasil, Waibel encontrou áreas para agricultura mal aproveitadas nos Campos limpos subtropicais do planalto do sul do Brasil, mas com clima favorável. Com exceção de algumas abordagens históricas no Rio Grande do Sul, como o plantio de trigo por imigrantes açorianos do final do século XVIII, plantio fracassado devido à infestação da ferrugem. Pela aquisição de todos os campos disponíveis pelos fazendeiros de gado luso-brasileiros, não havia mais terra devoluta para a lavoura. "Para a maioria dos brasileiros, a expressão "colonização do campo" é uma contradição em si, como, por exemplo, nadar na terra [...]." (WAIBEL, 1955a, p. 120).

Depois de tentativas malogradas de colonos alemães do Volga e de imigrantes poloneses e ucranianos a partir de 1870, foram fundados, a partir de 1930, alguns povoamentos com rotação de culturas, adubagem e pastagem (Terra Nova, Boqueirão) na região entre matas de araucária, capões e estepe no planalto paranaense. Como nas prairies dos Estados Unidos, o povoamento foi lento nos Campos limpos, de solos de pouca fertilidade. Dotados de capital, colonos holandeses foram extremamente exitosos na tentativa da junção da agricultura de rotação de culturas e adubagem paralelamente à intensa criação de gado na tão citada Colônia Carambeí. Um procedimento sem precedentes no Brasil (WAIBEL, 1948f, 1952). Como em futuras colonizações nos Campos, a existência de cooperativas bem organizadas desempenhou papel muito importante para a comercialização de produtos agrícolas e compra de materiais necessários.

Waibel reconheceu que a separação da lavoura e a criação de gado segundo o princípio do modelo de von Thünen só seria justificável com mercados distantes e não neste caso, onde o mercado estava próximo da capital Curitiba. No entanto, a venda de produtos agrícolas e laticínios poderia significar a abertura para novas chances comerciais ${ }^{53}$.

É surpreendente que, em seus estudos sobre a clara disposição espacial dos sistemas agrícolas dos pequenos colonos na mata, bem como da criação de gado e da lavoura nos campos do planalto no sul do Brasil, Waibel não tenha utilizado o termo "formação econômica", de sua autoria, empregado em seus estudos sobre a Sierra Madre de Chiapas, no México (WAIBEL, 1929), já que ele não apenas examinou o sistema agrícola, o objetivo da produção e a paisagem econômica, mas também as formas de vida dos atores.

É quase trágico que Waibel não mais pôde vivenciar a colonização dos imigrantes suábios do Danúbio em 1952, no Planalto do Paraná, mais precisamente perto de

\footnotetext{
${ }^{53}$ Waibel nunca aplicou diretamente a Lei de von Thünen em algum exemplo empírico em seus trabalhos no Brasil. Contudo, publicou os resultados dos seus estudos na Costa Rica em um artigo baseado em seu trabalho sobre "a lei de von Thünen e seu significado para a geografia agrária" ["Problemas da geografia agrária", Breslau, p. 47-78, 1933] (WAIBEL, 1948b), traduzido para o português. Ambos os trabalhos foram publicados em obra coletiva do CNG em 1958.
} 
Guarapuava (Colônia de Entre Rios). Esta imigração foi muito bem preparada e contou com ajuda do fundo de desenvolvimento internacional, dando abertura à lavoura nos campos. Outro exemplo é a Colônia Nova dos Menonitas, fundada em 1951, na Campanha de Bagé, no Rio Grande do Sul. Este desenvolvimento dependia da venda de terras pelos criadores de gado, que era muito esporádica e a venda somente era realizada em situações de desavenças por causa de heranças ou, propositadamente, para aumentar o valor das próprias terras. Depois da exploração do trigo e do arroz, os suábios do Danúbio cultivam soja e, em terrenos arrendados, cultivam a cevada para cerveja, economicamente muito lucrativa. A cevada é absorvida pela própria cooperativa fornecendo mais do que um terço da produção de malte necessário para a produção nacional de cerveja ${ }^{54}$. Atualmente, o plantio direto ajuda na prevenção de erosão.

$\mathrm{Na}$ avaliação sumária sobre a colonização agrícola europeia no sul do Brasil, Waibel apresentou sugestões e mencionou condições importantes para a obtenção do êxito (WAIBEL, 1955a, p. 134 ff.). Esta avaliação foi feita sob a premissa de novas imigrações. Neste contexto, Waibel ressaltou o aspecto ético na colonização: não somente os interesses do país deveriam ser respeitados como também os dos novos colonos. Durante o povoamento com imigrantes europeus, importantes condições climáticas e geográficas não foram consideradas. Os colonos alemães foram levados para a planície tropical e subtropical úmida do sul do Brasil e para a região tropical do Espírito Santo, onde as matas tropicais deveriam ser "colonizadas". Mais tarde, os imigrantes italianos obtiveram seus lotes, em parte no planalto, cuja qualidade de tierra-templada no Paraná e no Rio Grande do Sul mostraram-se muito favoráveis, especialmente adequadas para pessoas da Europa Central.

A exigência de Waibel de que cada nova colônia deveria, inicialmente, formar uma "unidade nacional" não deve ser interpretada de forma errônea. Não se pensou em áreas "nacionais" fechadas como no início da colonização e sim em áreas de etnias múltiplas, colônias com imigrantes alemães, italianos e holandeses junto a colônias luso-brasileiras - pelo menos no início, quando o idioma, a religião, a cultura, os costumes e usos no novo ambiente ainda tinham significado especial.

Waibel estava consciente de que esta sugestão era contraditória às leis brasileiras. Sua sugestão, no entanto, foi baseada em sua experiência e nos resultados empíricos dos seus estudos. Os problemas surgidos na colonização até então foram precipitadamente avaliados pelas repartições brasileiras como decorrentes de falta de vontade de integração dos imigrantes e de seus descendentes. A "brasilidade" somente poderá se desenvolver quando houver receptividade aos novos cidadãos pelo país anfitrião. Consciência das tradições e cultivo da herança cultural não devem ser confundidos com má vontade de integração, ainda mais

\footnotetext{
${ }^{54}$ Sobre o desenvolvimento da colonização dos Campos nos tempos pós-Waibel vide Kohlhepp (1969, 1989).
} 
quando seguidos pelo aprendizado do idioma do país, pela integração como cidadão consciente e pelo desempenho em prol do bem estar do país. Constatações que mantém valor ubiquitário até os dias de hoje.

Paralelamente à consideração das unidades religiosas, muito importantes para os imigrantes - sobretudo as do protestantismo - em um país católico, Waibel ressaltou especialmente a importância de boas escolas, cujo déficit levou à constituição de escolas privadas de cunho nacional próprio nas colônias e prejudicou a integração durante muito tempo. Uma observação válida de Waibel foi a de que somente bons professores poderiam tornar os filhos de imigrantes bons cidadãos, um assunto que atingiu suscetibilidades nacionais.

Waibel (1950/1984, p. 107) salientou claramente que a sua avaliação crítica sobre o assentamento de colonos alemães no sul do Brasil, sobretudo, em comparação ao dos Estados Unidos, referia-se exclusivamente ao desenvolvimento rural e não ao urbano ${ }^{55}$. As pequenas e médias cidades do sul do Brasil, fortemente marcadas por brasileiros de descendência alemã, desenvolveram-se muito bem no setor das pequenas e médias indústrias, representando assim o verdadeiro sucesso da imigração ${ }^{56}$.

$$
* * *
$$

Leo Waibel muito se interessou pelo trabalho sobre as zonas pioneiras do país, estudo que iniciou no Brasil, realizando somente a introdução geral da temática. Ele queria concluir na Alemanha a planejada segunda parte do estudo detalhado sobre as atuais zonas pioneiras da época. Valverde finalizou o manuscrito, publicado postumamente no Brasil (Waibel, 1955b/1984).

Waibel tentou realizar uma análise comparativa entre o Brasil e os Estados Unidos, usando o slogan que também é usado no Brasil - "marcha para o oeste" com base nas palavras chave "as últimas grandes reservas de terra do mundo ocidental". O slogan, associado ao conceito frontier de Turner nos Estados Unidos, tinha significado político-geográfico de fronteira, zona de limite de povoamento e zona de luta de complexos conflitos de interesse, assunto com o qual Pfeifer (1935) já havia se ocupado.

Para Waibel, a rápida expansão populacional e o plantio eram as condições básicas para a formação de uma zona pioneira. Ele examinou somente as zonas pioneiras dinâmicas, que ele caracterizou de forma exata, como segue:

\footnotetext{
55 Relativo ao trabalho de Waibel sobre a colonização europeia, publicado postumamente (WAIBEL, 1955a) e que estava planejada para ser publicado na Alemanha. Sobre as cidades não havia mais do que pequenas indicações de literatura e poucas notas nos seus diários, já que a situação urbana não era o objetivo dos seus estudos (vide prefácio de G. Pfeifer).

${ }^{56}$ Como exemplo, vide Kohlhepp (1968).
} 
[...] quando de repente, por um motivo qualquer a expansão da agricultura se acelera, quando uma espécie de febre atinge a população das imediações mais ou menos próximas e se inicia o afluxo de uma forte corrente humana [...], quando a agricultura e o povoamento provocam o que os americanos [...] denominam de boom ou rush. Então, os preços das terras elevam-se vertiginosamente, as matas são derrubadas, ruas e casas são construídas, povoados e cidades saltam da terra quase da noite para o dia, e um espírito de arrojo e de otimismo invade toda a população (WAIBEL, 1955b/1984, p. 80).

Durante o boom do café e o asfaltamento das estradas e ruas no oeste de São Paulo e no norte do Paraná houve uma transição nas novas cidades, do estado pioneiro ao estado moderno, um processo que levou somente de 10 a 20 anos.

Primeiramente, ele se dedicou às zonas pioneiras históricas: plantação de algodão no Maranhão no século XVIII; plantação de café no Rio de Janeiro e em São Paulo no século XIX, e, nas mais diversas fases, regiões de colonização com maioria de colonos alemães no sul do Brasil. No plantio de café, as ferrovias tornaram-se o "motor" da expansão muito rápida, ligada a extenso desmatamento. As designações regionais tinham os nomes das companhias ferroviárias: Mogiana, Paulista, Alta Sorocabana etc. As plantações de café eram o cenário típico das antigas fronteiras. Mesmo com solos férteis, as plantações sem adubagem levaram à exaustão de solos e ao fenômeno do declínio econômico e social - chamado por James (1938) de "bollow frontier" -, à migração, à criação extensiva de gado, fazendo-se necessária reestruturação econômica posterior.

As zonas pioneiras, atuais nos tempos de Waibel, também surgiram nas regiões de matas nos anos de 1940. Nisso, o transporte de vias férreas não era mais decisivo, surgindo cada vez mais o transporte rodoviário; as plantações e o plantio do café de pequenos e médios estabelecimentos não contavam mais com mão de obra escrava ou de imigrantes. A mão de obra era composta de atores provenientes das mais diversas regiões do país. Assim como a ampliação da zona pioneira do café em São Paulo estendeu-se até o Rio Paraná, separando a mata dos Campos, também a frente pioneira do norte do Paraná seguiu em direção ao oeste, sendo interrompida abruptamente em direção ao sul pelo limite de geadas.

Este foi o primeiro registro da atribuição ordenada de terras e com garantias de direito de uso numa colonização maior, favorecendo o desenvolvimento econômico dessa região pela terra muito fértil onde as terras roxas proporcionaram alta produção de café e mobilidade social nos anos 1950 e $1960^{57}$. Waibel somente vivenciou o início deste desenvolvimento (WAIBEL, 1948f).

Não somente as situações históricas, políticas e sociais no Brasil diferenciaram-se das dos Estados Unidos, como também as condições naturais ligadas a situações

\footnotetext{
${ }^{57}$ Vide L. Bernardes (1953), Kohlhepp (1975) e nota 92 neste texto.
} 
difíceis de relevo e grandes diferenças de clima e qualidade de solos. Mesmo com avanço coeso, a fronteira nos Estados Unidos tinha muitas vezes decorrência irregular, mas tratava-se de grande movimento em massas direcionado para o oeste até a fronteira climática da seca. Nos Estados Unidos, o avanço foi protelado, em parte, devido a grupos indígenas de cavaleiros, armas de fogo e organização precisa. No Brasil, pequenos grupos de colonos que não tinham mais qualquer ligação com o hinterland, avançaram sertão adentro. Ao contrário dos Estados Unidos, a especulação de terras era atributo da zona pioneira. Havia confrontos esporádicos com grupos indígenas que, na maioria das vezes, recuava para as profundezas da mata. Principalmente as densas florestas tropicais no Brasil eram motivos de impedimento.

Para Waibel, não havia a "marcha para o oeste" no Brasil, pois era de opinião que as zonas pioneiras desenvolviam-se além dos limites demográficos - muitas vezes, no meio das antigas regiões de colonização. Para ele estava claro "que o oeste do Brasil não é uma terra da promissão” (WAIBEL, 1955b/1984, p. 101). Ele conteve a euforia da época sobre o desenvolvimento do interior do país, pois estava convencido de que as melhores regiões já haviam sido tomadas. Para Waibel, as possibilidades estavam na intensificação da agricultura na região leste e habitada do Brasil e não na expansão para o oeste, sem excluir, no entanto, o progresso na produção de cash crops no interior. O boom, previsto por Waibel, está ligado ao plantio da soja desde os anos de 1970 e orientado para o mercado mundial.

A Amazônia como "espaço do futuro", segundo alguns nacionalistas, estava completamente fora de toda e qualquer hipótese científica. Waibel excluiu esta região de planicie tropical por motivos climáticos e de doenças tropicais. Muito antes da atual discussão sobre as consequências ecológicas e climáticas regionais do desmatamento de grandes áreas, esses fatores desempenharam papel muito menor na sua avaliação sobre a região amazônica do que as possibilidades inexistentes de venda dos produtos agrícolas de potenciais colonos. No mundo imaginário de Waibel, o imigrante europeu ainda continuava a ser requisitado.

Ele via as zonas pioneiras somente sob o ponto de vista agrícola e em zonas de matas. Sob a perspectiva política-ecológica, a expressão da frente pioneira abrange um sentido mais amplo nos dias de hoje, diferentes tipos de frentes pioneiras e grupos de atores com interesses econômicos adversos e grande potencial de conflito: "Seguro de sobrevivência versus orientação para o lucro ou extração de matérias-primas versus produção agrária" ${ }^{\text {58 }}$. Este aspecto é relevante no Brasil, tanto na região Amazônica, como na expansão do plantio da soja e da cana-deaçúcar nos Campos cerrados 59 .

\footnotetext{
${ }^{58}$ Kohlhepp; Coy (2010, p. 122) e Coy; Neuburger (2002). Coy publicou uma série de trabalhos sobre a frente pioneira, incluindo as cidades pioneiras (COY, 1990).

${ }^{59}$ Comparar com nota 101.
} 


\section{As atividades científicas de Leo Waibel no Brasil}

Quando Waibel estava trabalhando no Brasil, foi criada uma comissão para a "The World Land Use Survey", no âmbito do Congresso da IGU, em Lisboa, no ano de 1949, para a qual Waibel foi nomeado representante do Brasil, pelo mérito de seu trabalho na geografia agrária. Junto com Waibel estavam ainda Samuel van Valkenburg (Estados Unidos, chairman), L. Dudley Stamp (Grã-Bretanha), Hans Boesch (Suiça) e Pierre Gourou (Bélgica). Em dezembro de 1949 foi realizada reunião desta comissão em Worcester/Mass, na qual alguns países sugeriram, pela primeira vez, o levantamento mundial do uso da terra com mapas 1:1 milhão, volumes de interpretação e um sistema internacional geral de classificação (IGU, 1949), devido à situação alimentar problemática em muitos países.

Tanto na sua palestra de despedida "O que aprendi no Brasil" (WAIBEL, 1950/1984) ${ }^{60}$, proferida em 17 de agosto de 1950, no Conselho Nacional de Geografia, como na correspondência com Pfeifer, Waibel salientou repetidamente que fôra muito feliz com as condições de trabalho no CNG, apesar de alguns obstáculos burocráticos. A organização técnica de suas excursões era realizada por outros e em 1947 foi adquirido pelo CNG o primeiro veículo utilitário com motorista, conforme seu pedido, fazendo com que viagens de pesquisa e trabalhos de campo em excursões conjuntas se tornassem menos árduas. No tempo da estada de Waibel, havia no Brasil pouco mais de 500 quilômetros de estradas asfaltadas.

Colegas, parceiros de debates científicos e apoio linguístico de Waibel foram o Diretor do CNG, Fabio de Macedo Soares Guimarães ${ }^{61}$, e o grupo de colaboradores, como Orlando Valverde, Lysia e Nilo Bernardes, Pedro P. Geiger, Speridião Faissol e Walter Egler, tendo esse último posteriormente se tornado diretor do conhecido Museu Goeldi em Belém. Mais tarde todos os colaboradores lideraram o Departamento de Geografia do CNG. Esses geógrafos, chamados por Waibel de "terceira geração de estudantes", publicaram muitos trabalhos sobre colonização e geografia agrária no sul e no sudeste do Brasil ${ }^{62}$, levando adiante o pensamento de Waibel $^{63}$, que ainda orientou estes trabalhos até 1950.

\footnotetext{
${ }^{60}$ A palestra, publicada em português na Revista Brasileira de Geografia, foi traduzida para o alemão por Kohlhepp e publicado em Pfeifer (1971), como também em Pfeifer; Kohlhepp (1984). Os agradecimentos às personalidades oficiais e colaboradores do $\mathrm{CNG}$, em que ele também menciona expressamente seu motorista, foram publicados somente na versão original, em 1950.

${ }^{61}$ Vide, entre outros, "Divisão regional do Brasil" em Revista Brasileira de Geografia, 3 (2), 1941.

${ }^{62}$ Vide lista em Valverde (1971a, p. 126-127).

${ }^{63}$ Isso vale, sobretudo, para as monografias relativas à Geografia agrária do Brasil, de Valverde (1964, 1985).
} 
Alguns trabalhos mais antigos de Waibel foram publicados em tradução portuguesa no "Boletim Geográfico". Por iniciativa de Valverde, o CNG publicou, em 1958, doze trabalhos de Waibel no volume póstumo "Capítulos da Geografia Tropical do Brasil" (CNG, 1958) ${ }^{64}$. No volume "Clássicos da Geografia", publicado no ano de 1989 em comemoração aos 50 anos da Revista Brasileira de Geografia, Waibel foi honrado com a reedição do seu trabalho sobre a colonização europeia no sul do Brasil ${ }^{65}$.

Waibel se deu conta da grande importância dos trabalhos de historiadores, economistas e sociólogos brasileiros para a compreensão da pesquisa geográfica e citou como exemplos Capistrano de Abreu, Oliveira Viana, Caio Prado Jr. e Gilberto Freyre, autores que ele "descobriu" somente mais tarde (Waibel, $1950 / 1984$, p. 106). Como seus colaboradores ressaltaram, Waibel colocava cada vez mais a referência da sociologia em seus debates. Em publicações ele tratava grupos sociais de camponeses sem usar esse termo no sentido atual da geografia social. Sob o ponto de vista atual, questiona-se porque Waibel não sinalizou mais fortemente os déficits da política agrária e dos conflitos agrossociais ou mesmo a falta da reforma agrária, apesar de ter mencionado explicitamente os erros da colonização. Isto pode estar ligado a restrições que não permitiam a um conselheiro do CNG colocar-se contra a politica agrária de época em publicações. Em debates com peritos, no entanto, ele falava abertamente.

Tanto pelos métodos de pesquisa adotados e pelos resultados alcançados, quanto pela sua personalidade íntegra, inteiramente dedicada à ciência e à busca incessante de resultados, Waibel deixou no Brasil uma imagem que perdurará no tempo. Para Waibel, "a ética na profissão estava em primeiro plano: o compromisso ético de pesquisador e professor com relação à ciência, aos alunos e diante do público [...]" (PFEIFER, 1971, p. 1). Sua autoavaliação como "um trabalhador moroso" (WAIBEL, 1948e, p. 421) é contestada pela abundancia de suas viagens, pesquisas e publicações no Brasil.

Sua grande experiência nos trópicos, suas comparações fundamentadas, seu profundo conhecimento, os intensivos trabalhos de campo - quando não podia faltar a incômoda pergunta "o que vemos aqui?", e a avaliação critica das respostas ${ }^{66}$ - e a abordagem metódica inovadora para o Brasil impressionaram seus colaboradores, que sempre puderam contar com o seu incentivo. Para Waibel, a

\footnotetext{
${ }^{64}$ Entre outros, capítulo dos "Problemas da geografia agrária" (1933), em tradução de Egler, como todos os trabalhos publicados durante sua estada no Brasil.

${ }^{65}$ Original em Revista Brasileira de Geografia, 11 (2), p. 159-222, 1949 [Trad. em Pfeifer; Kohlhepp (1984)].

${ }^{66}$ Mesmo depois de exaustivo trabalho de campo, Waibel insistia nos debates detalhados à noite sobre os resultados do dia, sendo um exemplo para todos, também pela elaboração detalhada à luz do seu diário. Seus colaboradores mantiveram esse costume em futuras excursões - mesmo que isso não correspondesse ao modus vivendi brasileiro; vide nota 69.
} 
observação era "a ligação de ver e pensar" ${ }^{67}$. A qualidade dos relatórios elaborados em conjunto e suas publicações formuladas de maneira clara e exata aumentaram o conceito do CNG - "Meu trabalho aqui começa a dar frutos, o que está chamando a atenção do público"

O procedimento indutivo nas observações de campo levaram-no à procura do principio, o que, nos primórdios do seu trabalho cientifico, já o tinha levado à busca de princípios teóricos em contatos com Bruno Kuske, das ciências econômicas de Colônia, nos trabalhos de Johann Heinrich von Thünen ou Thies Hinrich Engelbrecht.

Sua maneira "alemã" de ser direto em debates e nas entrevistas, sua crítica aberta e fundamentada, sua insistência intransigente por clareza científica na versão léxica dos resultados e alguns comentários sarcásticos fizeram com que também tivesse adversários ${ }^{69}$. Um exemplo disso foi o caso de um geógrafo no Brasil, de quem Waibel contestou a qualificação científica, mas que mais tarde, com "pistolão", subiu à posição de liderança. Ou mesmo o caso do mencionado general, o qual Waibel repreendeu publicamente por causa do desconhecimento sobre o tema do local para a futura capital, deixando-o desacreditado. Neste sentido, seu comportamento foi pouco diplomático, mostrando que não estava disposto a aceitar argumentos que não fossem científicamente objetivos. Waibel não se adaptou ao jeito brasileiro, isto é, ao emprego de expressões mais suaves em debates técnicos, o que outrora era de bom tom.

Waibel chegou ao Brasil já com a saúde debilitada. As viagens pelo país sob condições modestas, principalmente os pernoites, a alimentação e a higiene precária cansaram-no "de maneira extraordinária"70. Acresçam-se, ainda, os efeitos não aparentes do choque que teve por causa de sua demissão em Bonn, as ofensas dos nazistas, os sentimentos de estar quase esquecido na Alemanha, a falta da pátria, a insegurança em relação ao futuro, a consciência de não possuir muito tempo de vida devido ao seu estado de saúde ${ }^{71}$.

As tentativas dos colegas de chamá-lo para a Alemanha durante o período de vigência do seu contrato com o CNG falharam, assim como a nomeação em 1948 à cátedra em Heidelberg. A possibilidade de nomeação para uma segunda cátedra

\footnotetext{
${ }^{67}$ Pfeifer (1971, p. 1).

${ }^{68}$ Carta de Waibel a Philippson, de 07.08.1950; vide Böhm (1991, p. 422); segundo documento 44, arquivo Inst. Geográfico de Bonn, IX-5.

${ }^{69}$ Informações pessoais de Orlando Valverde e Nilo Bernardes em inúmeras conversas com o autor desta contribuição. Carta particular de Pfeifer, de 20.08.1950, com relação a adversários de Waibel: “[...] já que Waibel dizia o que pensava”.

${ }^{70}$ Carta de Waibel para Pfeifer, de 10.10.1947, do Rio de Janeiro.

${ }^{71}$ Carta de Waibel a Pfeifer, de 01.11.1949, informações pessoais de Gottfried Pfeifer e diário sobre o Rio Grande do Sul, parte IV, p. 421 (WAIBEL, 1948e).
} 
em Bonn, hipótese que ele havia seriamente ponderado, também não foi bem sucedida, pois a cátedra acabou não sendo instituída ${ }^{72}$. Afinal, o retorno para a Alemanha levaria à perda da cidadania americana depois de dois anos ${ }^{73}$ - uma decisão extremamente problemática naquela época.

Depois de terminado seu trabalho no Brasil, Waibel aceitou o cargo de professor visitante na Universidade de Minnesota, em Minneapolis, Estados Unidos, nos anos acadêmicos de 1950/51. Muitas vezes Waibel considerou a possibilidade de retornar ao Brasil depois do seu trabalho junto à Universidade de Minnesota, no intuito de se dedicar a outras pesquisas e à elaboração da "Geografia dos trópicos" e da "Colonização do Brasil". Devido a um escândalo de corrupção no CNG, campanha da imprensa e influência exercida pelos militares sobre a política de pessoal, Waibel desistiu de voltar ao Brasil. A nomeação como professor da Universidade de Madison, Wisconsin, foi negada pela administração daquela Universidade, certamente por motivos de idade ${ }^{74}$. Com 63 anos, ele não queria mais exercer a atividade de ensino, queria "[...] escrever, e escrever novamente, para que eu possa ainda colher a safra brasileira" $"$.

Em agosto de 1951, muito hesitante e com certa reserva, Waibel viajou para a Alemanha com a esposa. O objetivo era consultar o ministério em Düsseldorf sobre a questão da compensação e indenização, como também sobre a regulamentação do seu salário e seus direitos a aposentadoria, além de encontrar colegas e se informar sobre a situação na Alemanha e da geografia alemã.

Em Heidelberg, sua terra natal, moravam suas duas irmãs e Pfeifer ${ }^{76}$, que era muito chegado a Waibel e que, entrementes, ocupava a cátedra de geografia, muito conceituada pelo fato de ter sido instituída por Alfred Hettner. Recém-chegado a Heidelberg e dominado por fortes emoções, Leo Waibel faleceu no dia 4 de setembro de 1951.

\footnotetext{
${ }^{72}$ Böhm (1991, p. 240-241).

${ }^{73}$ Carta de Waibel para Philippson, de 12.01.1947.

${ }^{74}$ Cartas de Waibel a Pfeifer, de 15.03.1951 e 08.05.1951, de Minneapolis.

${ }^{75}$ Carta de Waibel para Pfeifer, de 19.06.1951, de Minneapolis.

${ }^{76}$ Carta de Waibel para Philippson, de 07.08.1950: "Pfeifer [...] é o único entre os meus alunos e conhecidos que sofre psiquicamente por causa dos crimes dos nazistas, e sente uma responsabilidade [...]"; vide Böhm (1991, p. 423); segundo documentos 44 (arquivo do Inst. Geográfico de Bonn, acervo IX-5).
} 


\section{A estada de Waibel no Brasil como ponto de partida para uma cooperação científica entre Brasil e Alemanha no campo da geografia}

Quando o contrato de quatro anos de Waibel no CNG estava por terminar, ele aproveitou a oportunidade para convidar seu aluno Gottfried Pfeifer para uma estada de pesquisa no Brasil, de maio a setembro de 1950. Em 1949, Pfeifer estava em Hamburgo como professor e foi nomeado para a Universidade de Heidelberg. Antes de partir do Brasil, Waibel queria ainda realizar algumas excursões com Pfeifer, de modo a interessá-lo para a geografia dos trópicos. Naquela época, na Alemanha, era muito difícil organizar uma viagem ao exterior. A tentativa de viajar em 1949 mostrou-se inviável devido à exigência do Exit Permit, à compra de divisas, como também pela troca de universidade. Depois da constituição da República Federal da Alemanha, em 1949, persistiram os problemas com o reembolso dos custos de viagem e compra de divisas.

Pfeifer foi um dos primeiros geógrafos alemães que puderam realizar uma viagem deste tipo no período do pós-guerra, mas somente pelo fato de Waibel ter oferecido alojamento ao colega no Rio de Janeiro. $\mathrm{O} C \mathrm{CNG}$ financiou as excursões pelo país declarando o trabalho como missão oficial. Waibel adoeceu durante a permanência de Pfeifer, não podendo acompanhar toda a excursão para o Espírito Santo e para a Bahia.

Depois da excursão, Pfeifer publicou uma série de artigos sobre temas brasileiros $^{77}$. Nesta época foi instituído um centro de pesquisas junto à geografia humana em Heidelberg, com foco em temas sobre a América Latina ${ }^{78}$, especialmente sobre o Brasil. Pfeifer teve a preocupação e sentiu o compromisso ético de publicar e dar continuidade aos trabalhos de Waibel, uma vez que, por ter passado forçadamente tanto tempo no exterior, seus estudos não eram conhecidos na Alemanha. Nesse contexto, ele finalizou um manuscrito de Waibel destinado a ser publicado na Alemanha sobre a colonização europeia no sul do Brasil, aprofundando consideravelmente o trabalho homônimo publicado no Brasil. $\mathrm{Na}$ Alemanha, o trabalho foi publicado no "Colloquium Geographicum", em Bonn (WAIBEL, 1955a).

\footnotetext{
77 Assim, entre outros, Pfeifer (1952a, 1952b, 1953, 1956). Vide bibliografia de Pfeifer em KOHLHEPP, G. Gottfried Pfeifer. Geographisches Taschenbuch 1987/1988. Stuttgart, p. 133-157, 1987.

${ }^{78}$ Em 1962, juntamente com Wilhelm Lauer (Bonn), Pfeifer foi o responsável pela realização do abrangente projeto multidisciplinar de Puebla-Tlaxcala, da Associação Alemã de Pesquisas (DFG) no México, do qual participaram ainda diversos geógrafos alemães; vide PFEIFER, G. Relatório sobre um projeto alemão-mexicano. Geographische Zeitschrift, 52 (2), p. 128-151, 1964. Erdmann Gormsen trabalhou na Venezuela e no México, mais tarde Ursula Ewald também no México. O antigo grupo de Heidelberg, Felix Monheim (mais tarde em Aachen) e Albrecht Kessler (Hannover e Freiburg) trabalharam na Bolivia, Franz Tichy (Erlangen) trabalhou no México.
} 
O Congresso Internacional de Geografia, realizado no Rio de Janeiro, em $1956^{79}$ muito bem organizado pelo comité liderado por Hilgard O'Reilly Sternberg ${ }^{80}$-, do qual participaram, além de Pfeifer, representantes da geografia alemã, como Carl Troll, Herbert Wilhelmy ${ }^{81}$ e Herbert Lehmann, granjeou para a geografia brasileira reconhecimento internacional, uma forte ampliação das atividades de publicação dos pesquisadores nacionais e inúmeros contatos com o exterior. Os excolaboradores de Waibel, como Orlando Valverde, Lysia e Nilo Bernardes e Miguel Alves de Lima foram alguns dos responsáveis pela excelente organização das excursões durante o Congresso e conseguiram contornar problemas logísticos. $\mathrm{Na}$ ocasião, foram publicados guias de excursões muito bem fundamentados, em diversos idiomas, seguindo a tradição de Waibel $^{82}$.

Maria do Carmo Corrêa Galvão ${ }^{83}$, assistente universitária de O'Reilly Sternberg, foi para a Alemanha no final dos anos 1950, como primeira candidata brasileira ao doutorado. Trabalhou com Carl Troll, que foi presidente do IGU de 1960 a 1964. Nesse meio tempo, Karl Heinz Paffen (Bonn) iniciou pesquisas ecológicas sobre o $\mathrm{Brasil}^{84}$.

No início dos anos 1960, Pfeifer intensificou as atividades sobre o Brasil no Instituto de Geografia da Universidade de Heidelberg. No semestre de verão no ano de 1961, O'Reilly Sternberg aceitou o cargo de professor visitante na Universidade de Heidelberg e convidou, em 1962, o seu assistente em Heidelberg, Gerd Kohlhepp, para realizar trabalhos de campo para a sua dissertação no Brasil (1962/63). Na fase anterior à instalação do Serviço Alemão de Intercâmbio Acadêmico (DAAD) ainda não havia bolsas para doutorandos e, por isso, esse tipo de convite somente era realizável com o apoio do Ministério da Cultura do Brasil $^{85}$, que financiou a passagem aérea. Uma longa excursão conjunta, em 1962,

\footnotetext{
79 Victor Antônio Peluso Júnior (Florianópolis/Santa Catarina) foi presidente do Comitê Nacional do Brasil na IGU.

${ }^{80}$ Hilgard O'Reilly Sternberg foi diretor do Centro de Pesquisas de Geografia do Brasil, da Universidade Federal do Rio de Janeiro, e vice-presidente da IGU de 1952 a 1956, além de primeiro vice-presidente da IGU de 1956 a 1960; vide Sternberg (1956, 1959).

${ }^{81}$ Wilhelmy $(1958,1966)$.

${ }^{82}$ Vide, entre outros, Valverde (1957).

${ }^{83}$ Vide GALVÃO, M. do C. C. Das Ruwergebiet (a região do Ruwer: mudanças da paisagem e estrutura social). Bonn: Inst. Geográfico, 1964.

${ }^{84}$ Paffen (1957, entre outros). Lehmann (1958) trabalhou - na Alemanha Oriental (RDA) sobre o sul do Brasil e sobre as publicações de Waibel. Em uma dissertação não publicada (PH Karl Liebknecht, Potsdam, 1971), I. Hönsch ocupou-se da contribuição de Leo Waibel para a geografia agrária.

${ }^{85}$ A dissertação de Kohlhepp (1968) sobre geografia industrial tinha o objetivo de examinar o setor industrial da economia e com isso o desenvolvimento urbano de uma região no sul do Brasil. O trabalho foi publicado como Volume 1 da nova subsérie "Contribuições à geografia
} 
de O'Reilly Sternberg com o seu grupo de trabalho e com Pfeifer e Kohlhepp, à Santa Catarina, formou a base de trabalho conjunto com o Centro de Pesquisas de Geografia do Brasil (CPGB) ${ }^{86}$, que, depois da emigração de O'Reilly Sternberg para os Estados Unidos, em 1963, teve seguimento com Maria do Carmo Corrêa Galvão e Bertha K. Becker no Rio de Janeiro, com O’Reilly Sternberg junto à Universidade da California, em Berkeley, e com Kohlhepp, em Frankfurt e Tübingen.

Quando no início dos anos 1960 foi cogitada a criação de um centro regional interdisciplinar para pesquisas e ensino na Universidade de Heidelberg, pensou-se primeiramente em estudos sobre a América Latina - o que, infelizmente, não foi realizado, pois ainda não havia campo tanto na geografia como na pesquisa sobre a América Latina em Heidelberg. Em 1962 foi escolhido o Sul da Ásia como região de estudos e, assim, foi criado o Instituto do Sul da Ásia.

A intensidade dos trabalhos sobre a geografia do Brasil em Heidelberg ${ }^{87}$ passou por nova fase com a viagem de pesquisas de três meses de Pfeifer e Kohlhepp, em 1965, ao sul do Brasil e ao Brasil Central. Juntamente com Valverde e seu grupo de trabalho no CNG no Rio de Janeiro foram realizadas pesquisas "nos caminhos de Waibel"88. Pfeifer conseguiu desenvolver uma cooperação científica tanto com o $\mathrm{CNG}^{89}$ como com o CPGB, apesar das tensões políticas existentes na época entre os líderes brasileiros dos dois grupos de trabalho. Daí surgiu a oportunidade da docência de Valverde como professor visitante em Heidelberg no semestre de verão de 1967. Valverde tinha muito orgulho do seu trabalho com Waibel. Nos anos de 1967 e 1970, as geógrafas brasileiras Regina Mousinho de Meis e Maria Novaes Pinto, do Rio de Janeiro, encontraram-se em Heidelberg. Os colegas brasileiros e alemães publicaram em volumes da série "Heidelberger Geographische Arbeiten" $15(1966)^{90}$ e 34 (1971) $)^{91}$ os resultados das suas pesquisas.

cultural e econômica do Brasil", da "Heidelberger Geographische Arbeiten", série que não teve mais prosseguimento depois que Pfeifer se tornou Professor Emeritus em 1969.

${ }^{86}$ Mais tarde, Instituto de Geociências da Universidade Federal do Rio de Janeiro (UFRJ), sua nova denominação depois da transferência da capital.

${ }^{87}$ No ano de 1964, todos os trabalhos de Waibel, ainda em idioma português, foram traduzidos para o alemão por Kohlhepp e preparados para publicação.

${ }^{88}$ Pfeifer; Kohlhepp (1966), Pfeifer (1967, entre outros), Kohlhepp (1966).

${ }^{89}$ Mais tarde denominado Instituto Brasileiro de Geografia, como parte do Instituto Brasileiro de Geografia e Estatística (IBGE).

${ }^{90}$ Estudos de Heidelberg sobre geografia cultural - publicação comemorativa aos 65 anos de G. Pfeifer.

${ }^{91}$ GLASER, G. (Org.) Beiträge zur Geographie Brasiliens (contribuições para a geografia do Brasil) (= Heidelberger Geogr. Arb. N. 34). Heidelberg: Selbstverlag Geogr. Institut, 1971b comemoração dos 70 anos de G. Pfeifer. 
O Simpósio da Geografia Agrária, realizado em 1968, em Heidelberg, em comemoração aos 80 anos de Leo Waibel (Pfeifer, 1971), contou com forte presença de geógrafos alemães, demostrando a importância do trabalho de Waibel na Alemanha. Em sua introdução à geografia agrária tropical, Walter Manshard (1968) consagrou-o: "Leo Waibel, o fundador da geografia agrária dos trópicos".

Depois dos trabalhos de campo, no ano de 1970, Kohlhepp pôde dar continuidade às ideias de Waibel em seu trabalho de livre docência sobre a colonização agrária e as zonas pioneiras no norte do Paraná - uma região que foi colonizada na época da estada de Waibel e que se tornou a região mais importante de plantio de café no Brasil nos anos de $1960^{92}$.

Desde os tempos de Valverde como professor visitante na Universidade de Heidelberg, ambicionava-se um acordo legal de cooperação de pesquisa na região da Amazônia, a ser firmado entre o Instituto de Geografia da Universidade de Heidelberg e o Instituto Brasileiro de Geografia (IBG) do IBGE ${ }^{93}$ (grupo de trabalho Valverde) no Rio de Janeiro, a fim de garantir a participação de pesquisadores alemães. Em agosto de 1971, o acordo foi assinado. Entrementes, em 1969, o projeto iniciado por Valverde sobre empreendimentos de pesquisa do IBG com os geógrafos de Heidelberg (Gottfried Pfeifer, Hanna Bremer, Gisbert Glaser, Gerd Kohlhepp) foi aprovado pela Fundação Volkswagen que, entre outras coisas, colocou meios financeiros à disposição para equipamentos técnicos, inclusive o motor para um barco de pesquisas que serviria às pesquisas na Amazônia. O barco seria batizado de "Leo Waibel", em homenagem ao seu trabalho no Brasil e em lembrança a sua esperança de conhecer a Amazônia, sonho que não pode ser realizado durante a sua estada no Brasil.

No tempo da estada de Waibel no Brasil, a Amazônia ainda não havia sido explorada e não era uma região adequada para trabalhos de pesquisa sobre a geografia humana. A região também deixou de ser opção para o estudo das zonas pioneiras que se desenvolveram somente depois dos programas estatais de colonização nos anos 1970 e que, em parte, transcorreram de maneira caótica. A almejada construção do barco não foi realizada devido a diversos obstáculos na época da ditadura militar no Brasil (1964-1985), impedimentos nacionais de natureza político-financeira e problemas administrativos no IBGE. O rápido desenvolvimento da construção de estradas na Amazônia possibilitou novos acessos e, através das medidas de colonização agrária, deu-se uma ampliação temática do empreendimento pelo lado alemão.

As pesquisas planejadas por Glaser $(1969,1971$ a) e Bremer (1971, 1973) foram realizadas somente em parte. Glaser, que já trabalhara no sudoeste da Amazônia e

\footnotetext{
${ }^{92}$ A metrópole regional de Maringá, no noroeste do Paraná, foi fundada em 1947, sendo a primeira cidade cuja fundação se realizou com a criação de uma pista para pouso e decolagem de aviões na floresta tropical (em 2010 tinha 326.000 habitantes).

${ }^{93}$ Vide nota 89.
} 
na parte central do Brasil em 1968, seguiu depois para a UNESCO em Paris. Bremer foi nomeada para a Universidade de Colônia ${ }^{94}$ e Kohlhepp aceitou a chamada para a Universidade de Frankfurt em 1972. Em março de 1973, o programa de pesquisas foi incluído no acordo Alemanha-Brasil de cooperação científica e tecnológica ${ }^{95}$. Com o acordo estava assegurada a licença para a realização de pesquisas, pois o governo militar tinha desconfiança em relação aos projetos de pesquisa de estrangeiros na Amazônia. Assim, as temáticas dos trabalhos puderam ser abrangentemente ampliadas por Kohlhepp (1976, 1979 entre outros $)^{96}$. O centro de estudos sobre o Brasil, em Heidelberg, finalizou suas atividades em 1972, quando Pfeifer tornou-se emérito, e depois da mudança para outras Universidades e para a UNESCO de todos aqueles envolvidos nos projetos.

Depois de aceitar a cátedra de Tübingen como sucessor de Herbert Wilhelmy, Kohlhepp pôde desenvolver, a partir de 1978, os estudos sobre a América Latina, tendo o Brasil como foco principal ${ }^{97}$. Graças à continuidade da cooperação com os colegas brasileiros, puderam ser feitos acordos com universidades brasileiras e realizados programas de intercâmbio financiados pelo DAAD para estudantes da área de "Geografia de países em desenvolvimento" (foco América Latina), como, por exemplo, com a UFRJ, no Rio de Janeiro. Como representante da geração de "netos de Waibel" e com novos campos de pesquisas, ele pôde dar continuidade aos contatos com colaboradores e colegas de Waibel no Brasil por meio de novos projetos, em excursões conjuntas no Brasil, bem como em conferências no Brasil e na Alemanha ${ }^{98}$.

Com base em suas pesquisas na Amazônia, os geógrafos Bertha K. Becker ${ }^{99}$, do instituto parceiro de Tübingen no Rio de Janeiro (UFRJ), e Gerd Kohlhepp

\footnotetext{
${ }^{94}$ Hanna Bremer publicou uma síntese das suas pesquisas nos trópicos no volume "Os trópicos" (BREMER, 1999).

${ }^{95} \mathrm{Na}$ verdade, isto se referia ao Instituto Geográfico de Heidelberg, cujos participantes dos projetos já o tinham deixado. Dado que os meios financeiros não podiam ser transferidos do Estado de Baden-Württemberg para Frankfurt, no Estado de Hessen (problemas específicos do federalismo alemão), o programa de pesquisas deveria ser administrado desde a Universidade de Heidelberg!

${ }^{96}$ Do lado alemão, o programa teve continuidade com os projetos de Kohlhepp; vide, também, em síntese temática, Kohlhepp (1987).

${ }^{97}$ Vide Kohlhepp (2000).

98 Orlando Valverde foi condecorado, em homenagem às suas pesquisas (VALVERDE, 1979/1989, 1989 entre outros), no ano de 1991, com prêmio pelas pesquisas em países em desenvolvimento da Universidade de Gießen (KOHLHEPP, 1991). Os resultados de pesquisas dos counterparts na geografia brasileira, de Valverde, de Irene Garrido Filha, de O'Reilly Sternberg, de Bertha K. Becker, de Lia Osório Machado, entre outros, foram publicados em Kohlhepp; Schrader (1987) ou em séries alemãs: Sternberg (1975), Kohlhepp (1983, 1987 entre outros).

${ }^{99}$ Becker (1990, 2004 entre outros).
} 
(chairman), foram nomeados, em 1993, membros do grupo multidisciplinar do International Advisory Group (IAG) do "Programa Piloto para a conservação das florestas tropicais do Brasil" (PPG7), do Banco Mundial, do Governo do Brasil e dos países do G7. A partir de 2003, Martin Coy também se tornou membro do IAG.

Mais tarde foi possível realizar parcerias com outras universidades, entre elas a Universidade de Santa Cruz do Sul (Rio Grande do Sul), onde trabalha Virginia E. Etges. Em sua tese defendida, em 1997, em São Paulo, ela se ocupou com o trabalho de Waibel sobre a geografia agrária (Etges, 2000).

Nos "Tübinger Beiträge zur Geographischen Lateinamerikaforschung” (TBGL) i.é. "Contribuições de Tübingen para a pesquisa geográfica da América Latina" foi publicada uma série de dissertações de doutorandos alemães e brasileiros (até o vol. 31, 2007) que levaram adiante muitas sugestões de Waibel com relação à colonização agrária, ao desenvolvimento da frente pioneira e à agricultura de pequenos colonos ${ }^{100}$. As pesquisas do grupo de trabalho de Tübingen no Brasil Central e no "Projeto Pantanal"101 tinham como objetivo os processos de desenvolvimento econômico e social regional e a análise do uso agrário nos Campos cerrados, cujo potencial agrário já era de suposição de $\mathrm{Waibel}^{102}$. Além disso, foi prestada contribuição pela análise das causas sócio-ecológicas dos problemas ambientais para a pesquisa de base da ecologia tropical e para o debate homemmeio ambiente nos trópicos. Foram elaboradas sugestões quanto à compatibilidade ambiental com consequente desenvolvimento regional sustentável para a planejada implementação ${ }^{103}$.

${ }^{100}$ Lücker (1986), Coy (1988), Neuburger (2002), entre outros. A última dissertação, de Rogério R. Mororó, sob a supervisão do autor, foi concluída em novembro de 2012. Na série "Pequenos trabalhos no Instituto de Geografia da Universidade de Tübingen" foram publicados trabalhos selecionados de mestrado (Diploma) do grupo de trabalho do Centro de Pesquisas sobre a América Latina.

101 Coy; Lücker (1993), Coy (1990, 2003), Kohlhepp (1995), Blumenschein (2001), Neuburger (2002), entre outros - no âmbito do programa bilateral alemão-brasileiro SHIFT (BMBF-CNPq) foi realizado o projeto "Estrutura socioeconômica e dinâmica dos impactos ambientais na Bacia do Alto Rio Paraguai - Mato Grosso" (Pantanal e arredores), em cooperação com um grupo de trabalho multidisciplinar, da Universidade Federal do Mato Grosso (UFMT), em Cuiabá.

102 Os resultados conjuntos foram apresentados em 12 cadernos, em português, como "Diagnóstico sócio-econômico da Bacia do Alto Rio Paraguai" (Cuiabá/Tübingen 1994/95), que também serviu de material básico para as repartições de planejamento; vide Kohlhepp (2000).

${ }^{103}$ Com abordagem interdisciplinar e participação internacional, foi posteriormente planejado um projeto "Desenvolvimento regional sustentável da periferia amazônica", que tinha como objetivo uma análise do processo de desenvolvimento socioeconômico e político-ecológico no Brasil e na Bolivia (COY; KOHLHEPP, 2005). 
Com base em contatos já existentes de pesquisadores e das atividades posteriores de todos os doutorandos brasileiros e de alguns colaboradores em Tübingen como professores de geografia em universidades brasileiras ${ }^{104}$ e instituições de cooperação para o desenvolvimento, formou-se uma abrangente rede de contatos. Esta rede teria sido muito útil para os trabalhos na época de Leo Waibel que, ao contrário dos seus colegas franceses, sentiu grande falta desse meio. Por causa da sua morte prematura não pôde mais desenvolver pessoalmente os contatos para acompanhar suas pesquisas. Não obstante, suas pesquisas foram desenvolvidas através dos seus discípulos diretos e indiretos em três gerações no Brasil e na Alemanha. Depois da fase em Tübingen, está sendo dada continuidade a muitas abordagens temáticas na pesquisa sobre o Brasil pelos ex-colaboradores de Kohlhepp: Martin Coy e seu grupo de trabalho em Innsbruck; Martina Neuburger, em Hamburgo; Frank Zirkl, em Eichstätt; Rainer Rothfuß, em Tübingen, e Dörte Segebart, em Berlim, contando naturalmente com novos contatos e colocação autônoma de novos projetos científicos.

Depois das Universidades de Heidelberg, Frankfurt e Tübingen, outros Institutos de Geografia em universidades na Alemanha, como Bonn, Kiel e Passau também trabalharam, desde o final da década dos anos 1980, sobre temas brasileiros da geografia humana, em dissertações e outros projetos de pesquisas ${ }^{105}$. No grupo de pesquisas de Rainer Wehrhahn, em Kiel, o Brasil é um dos temas centrais dos estudos regionais.

Leo Waibel também é tema de trabalho para as mais novas gerações, tanto nos Estados Unidos como no Brasil. Stephen Bell, da Universidade da Califórnia, em Los Angeles, ocupa-se de um estudo sobre Waibel no que diz respeito à geografia histórica. A colega brasileira Virginia E. Etges publicou um estudo sobre a geografia agrária de Waibel neste volume dedicado a ele na Alemanha.

Nos últimos 10 a 15 anos, a pesquisa regional de muitas disciplinas especializadas sofreu interrupção nas universidades alemãs, por causa de aposentadorias de professores, cancelamentos de cátedras e mudanças das disciplinas nas cátedras ${ }^{106}$, atingindo também a pesquisa sobre a América Latina. Acresça-se, ainda, que os principais programas de pesquisas de muitos anos, estudos regionais e programas

${ }^{104}$ Marcelo Lopes de Souza (Rio de Janeiro/UFRJ), Cicilian L. Löwen (Ponta Grossa/PR), Wolf-Dietrich Sahr (Curitiba/PR), Ivo M. Theis (Blumenau/SC), Dieter R. Siedenberg (Ijuí/RS), Arno C. Lehnen (Porto Alegre e Canoas/RS), Erica Karnopp (Santa Cruz do Sul/RS), Karl Henkel (Belém/PA) e Jutta Gutberlet (Vancouver/Canada).

${ }^{105}$ Assim, entre outros, o trabalho de livre docência de E. Struck sobre núcleos habitacionais no Brasil, desenvolvimento e estrutura em três áreas de povoamento no Espírito Santo (= Passauer Schriften zur Geographie, N. 11, Passau, 1992).

106 Vide workshop "competência regional em tempos de globalização" em ADLAF (Arbeitsgemeinschaft Deutsche Lateinamerika-Forschung = Associação Alemã de Pesquisas sobre a América Latina) (org.) Perspectivas da pesquisa alemã sobre América Latina, ADLAF-Info 3, p. 3-8, 2004. 
de intercâmbio com universidades nas regiões de trabalho foram cancelados. Assim, a continuidade da cooperação científica foi interrompida justamente num período em que os países emergentes poderiam participar dos programas como counterparts, com meios financeiros próprios.

As pesquisas de Leo Waibel nos trópicos foram iniciadas ainda no período de ocupação colonial alemã na África. Naquela época, os processos econômicos e as estruturas da geografia econômica ainda eram vistas sob o prisma europeu, isto é, pelo ângulo dos senhores colonizadores. No decorrer dos seus trabalhos científicos, Waibel mudou para regiões tropicais - unidades políticas autônomas e Estados Nacionais constituídos há mais de 120 anos, com espaço vital e econômico próprios. Leo Waibel estava convencido de que a terminologia da geografia humana, desenvolvida nas zonas temperadas, não era adequada para os trópicos, e pleiteou uma disciplina que deveria ter o nome de "geografia tropical". $\mathrm{Na}$ condição de maior país tropical do mundo, Waibel via o Brasil como uma chance única de colocar em prática este tipo de disciplina. Por causa da sua morte prematura, seus planos não puderam ser realizados e suas monografias não puderam ser concluídas, como "Os trópicos como espaço futuro da humanidade", "A América tropical", "A colonização do Brasil" (WAIBEL, 1948e, p. 421) e a "Geografia econômica dos trópicos".

Os trabalhos de Leo Waibel receberam homenagem especial no Congresso da IGU no Rio de Janeiro, em 1982, quando Nilo Bernardes ressaltou o seu significado para a geografia brasileira (BERNARDES, 1983), pela divisão da qualidade de pesquisas de geografia do Conselho Nacional de Geografia em duas fases: "a primeira antes de Leo Waibel" e "a segunda depois de Waibel tendo, com ele, alcançado nível muito mais alto" (VALVERDE, 1971a, p. 127). O período pós-Waibel mostrou que o seu trabalho no Brasil deu o impulso para o tão almejado e intenso intercâmbio científico entre geógrafos brasileiros e alemães que ele não pôde mais estabelecer. $\mathrm{O}$ intercâmbio levou a efeitos positivos durante muitos anos.

\section{Referências}

BECKER, B. K. Amazônia (= Série Princípios). São Paulo: Ática, 1990.

BECKER, B. K. Amazônia: geopolítica na virada do terceiro milênio. Rio de Janeiro: Garamond, 2004. 
BERNARDES, L. M. Cavalcanti. O problema das frentes pioneiras no Estado do Paraná. Revista Brasileira de Geografia, 15 (3), p. 335-384, 1953.

BERNARDES, N. Leo Waibel. Revista Brasileira de Geografia, 14 (2), p. 199201, 1952.

BERNARDES, N. Address delivered on the occasion of the closing session of the Second Latin-American Regional Conference of the IGU, Rio de Janeiro (20.08.1982). IGU-Bulletin, N. 33, p.12-22, 1983.

BLUMENSCHEIN, M. Landnutzungsveränderungen der modernisierten Landwirtschaft in Mato Grosso, Brasilien (Mudanças de uso da terra na agricultura modernizada de Mato Grosso). Tübinger Beiträge zur Geographischen Lateinamerikaforschung (= TBGL N. 21). Tübingen: Ed. Instituto Geográfico, 2001.

BÖHM, H. Leo Waibel. In: BÖHM, H. (org.) Beiträge zur Geschichte der Geographie an der Universität Bonn (= Colloquium Geographicum N. 21). Bonn: Ferd. Dümmlers, p. 228-241, 1991.

BRANDT, B. Kulturgeographie von Brasilien (Geografia cultural do Brasil). Stuttgart: J. Engelhorns Nachf., 1922.

BREMER, H. Flüsse, Flächen- und Stufenbildung in den feuchten Tropen. Würzburger Geogr. Arb., N. 35, 1971.

BREMER, H. Der Formungsmechanismus im tropischen Regenwald Amazoniens. Zeitschr. f. Geomorph., NF, Suppl. 17, p. 195-222, 1973.

BREMER, H. Die Tropen: geographische Synthese einer fremden Welt im Umbruch (Os trópicos). Berlin; Stuttgart: Gebr. Borntraeger, 1999.

CARVALHO, C. Delgado de. Geografia do Brasil. Rio de Janeiro: Impr. Artísticas, 1913.

CNG [Conselho Nacional de Geografia]. Histórico da criação do Conselho Nacional de Geografia. Revista Brasileira de Geografia, 1 (1), p. 9-18, 1939.

CNG. Capítulos de geografia tropical e do Brasil. Rio de Janeiro: IBGE, $1958 / 1979$. 
COY, M. Regionalentwicklung und regionale Entwicklungsplanung an der Peripherie in Amazonien: Probleme und Interessenkonflikte bei der Erschließung einer jungen Pionierfront am Beispiel des brasilianischen Bundesstaats Rondônia (Desenvolvimento e planejamento regional na periferia da Amazônia) Tübinger Beiträge zur Geographischen Lateinamerikaforschung (= TBGL N. 5). Tübingen: Ed. Instituto Geográfico, 1988.

COY, M. Pionierfront und Stadtentwicklung in Nord-Mato Grosso (Brasilien). Geographische Zeitschrift, 78 (2), p. 115-134, 1990.

COY, M. Regionalentwicklung im südwestlichen Amazonien. In: KOHLHEPP, G. (org.) Brasilien: Entwicklungsland oder tropische Großmacht des 21. Jhdts.? (Brasil: país em desenvolvimento ou potência tropical do século 21?) Tübingen: Attempto, p. 215-238, 2003.

COY, M.; LÜCKER, R. Der brasilianische Mittelwesten: Wirtschafts- und sozialgeographischer Wandel eines peripheren Agrarraumes (O Centro Oeste brasileiro: mudança da geografia econômica e social de uma região agrária periférica). Tübinger Beiträge zur Geographischen Lateinamerikaforschung (= TBGL N. 9). Tübingen: Ed. Instituto Geográfico, 1993.

COY, M.; NEUBURGER, M. Brasilianisches Amazonien: Chancen und Grenzen nachhaltiger Entwicklung. Geogr. Rundschau, 54 (11), p. 12-20, 2002.

COY, M.; KOHLHEPP, G. (org.) (2005): Amazônia sustentável: desenvolvimento sustentável entre políticas públicas, estratégias inovadoras e experiências locais. Tübinger Beiträge zur Geographischen Lateinamerikaforschung (= TBGL N. 28). Tübingen; Rio de Janeiro: Ed. Instituto Geográfico; Garamond, 2005.

DEFFONTAINES, P. Geografia humana do Brasil. Revista Brasileira de Geografia, 1 (1), 1939 [re-edição em Revista Brasileira de Geografia, 50 (1), número especial, p. 267-317, 1988].

DENIS, P. Le Brésil au XXème siècle. Paris: Libr. Armand Colin, 1909.

ETGES, V. E. Geografia agrária: a contribuição de Leo Waibel. Santa Cruz do Sul: EDUNISC, 2000.

GLASER, G. Der Zinnstein-Abbau in Rondônia. Geographische Zeitschrift, 57 (4), p. 241-267, 1969. 
GLASER, G. Neue Aspekte der Rinderweidewirtschaft in Zentralbrasilien. In: GLASER, G. (org.) Beiträge zur Geographie Brasiliens (= Heidelberger Geogr. Arb. N. 34). Heidelberg: Selbstverlag Geogr. Institut, p. 19-42, 1971 a.

GLASER, G. (org.) Beiträge zur Geographie Brasiliens (= Heidelberger Geogr. Arb. N. 34). Heidelberg: Selbstverlag Geogr. Institut, 1971 b.

GUIMARÃES, F. de Macedo Soares. O Planalto Central e o problema da mundança da capital do Brasil. Revista Brasileira de Geografia, 11 (4), p. 471$542,1949$.

GUTERSOHN, H. São Paulo: Natur und Wirtschaft. Vierteljahresschrift d. Naturforsch. Ges. Zürich, N. 85, p. 149-255, 1940.

HETTNER, A. Das südlichste Brasilien (Rio Grande do Sul). Zeitschr. d. Ges. f. Erdkunde zu Berlin, N. 26, p. 85-144, 1891.

IGU (org.) The world land use survey: report of the commission. Worcester/Mass.: International Geographical Union, 1949.

JAMES, P. E. The coffee lands of Southeastern Brazil. Geogr. Review, N. 22, p. 225-244, 1932.

JAMES, P. E. The changing patterns of population in Sao Paulo State, Brazil. Geogr. Review, N. 28, p. 353-362, 1938.

KOHLHEPP, G. Die deutschstämmigen Siedlungsgebiete im südbrasilianischen Staate Santa Catarina: geographische Grundlagen und Probleme ländlicher und städtischer Kolonisation unter besonderer Berücksichtigung der wirtschaftlichen Entwicklung. Heidelberger Studien zur Kulturgeographie (= Heidelberger Geogr. Arb. N. 15). Wiesbaden: Franz Steiner, p. 219-244, 1966.

KOHLHEPP, G. Industriegeographie des nordöstlichen Santa Catarina (Südbrasilien): ein Beitrag zur Geographie eines deutschbrasilianischen Siedlungsgebietes (Geografia industrial do Nordeste de Santa Catarina) (= Heidelberger Geogr. Arb. N. 21). Heidelberg: Ed. Instituto Geogr., 1968.

KOHLHEPP, G. Types of agricultural colonization of subtropical Brazilian Campos limpos. Revista Geográfica, N. 70, p. 131-155, 1969. 
KOHLHEPP, G. Agrarkolonisation in Nord-Paraná: wirtschafts- und sozialgeographische Entwicklungsprozesse einer randtropischen Pionierzone unter dem Einfluss des Kaffeeanbaus (Colonização agrária no Norte do Paraná) (= Heidelberger Geogr. Arb. N. 41). Wiesbaden: Franz Steiner, 1975.

KOHLHEPP, G. Planung und heutige Situation staatlicher kleinbäuerlicher Kolonisationsprojekte an der Transamazônica. Geographische Zeitschrift, 64 (3), p. 171-211, 1976.

KOHLHEPP, G. Brasiliens problematische Antithese zur Agrarreform: Agrarkolonisation in Amazonien Evaluierung wirtschafts- und sozialgeographischer Prozessabläufe an der Peripherie im Lichte wechselnder agrarpolitischer Strategien. In: ELSENHANS, H. (org.) Agrarreform in der Dritten Welt. Frankfurt am Main; New York: Campus, p. 471-504, 1979.

KOHLHEPP, G. Strategien zur Raumerschließung und Regionalentwicklung im Amazonasgebiet: zur Analyse ihrer entwicklungspolitischen Auswirkungen. In: BUISSON, I.; MOLS, M. (org.) Entwicklungsstrategien in Lateinamerika in Vergangenheit und Gegenwart. Paderborn: Ferd. Schöningh, p. 175-193, 1983.

KOHLHEPP, G. Amazonien: Regionalentwicklung im Spannungsfeld ökonomischer Interessen sowie sozialer und ökologischer Notwendigkeiten (Amazônia: desenvolvimento regional no conflito de interesses econômicos e de necessidades sociais e ecológicas) (= Problemräume der Welt N. 8). Köln: Aulis, 1987.

KOHLHEPP, G. Raumwirksame Tätigkeit ethnosozialer Gruppen in Brasilien: am Beispiel donauschwäbischer Siedler in Entre Rios/Paraná. In: ROTHER, K. (org.) Europäische Ethnien im ländlichen Raum der Neuen Welt (= Passauer Schriften zur Geographie N. 7). Passau: Passavia, p. 31-46, 1989.

KOHLHEPP, G. Laudatio für Orlando Valverde. In: SCHOLZ, U. (org.) Tropischer Regenwald als Ökosystem $(=$ Gießener Beiträge zur Entwicklungsforschung N. 19, Reihe I). Gießen: Tropeninstitut, p. 133-139 e 147$150,1991$.

KOHLHEPP, G. (org.) Mensch-Umwelt-Beziehungen in der PantanalRegion von Mato Grosso, Brasilien: Beiträge zur angewandten geographischen Umweltforschung (Relações homem-meio ambiente na região do Pantanal). Tübinger Beiträge zur Geographischen Lateinamerikaforschung (= TBGL N. 12). Tübingen: Ed. Instituto Geográfico, 1995. 
KOHLHEPP, G. Forschung und Lehre am Lehrstuhl für Wirtschafts- und Sozialgeographie. In: KOHLHEPP, G.; PFEFFER, K.-H. (org.) 100 Jahre Geographie an der Universität Tübingen (= Tübinger Geogr. Studien N. 118). Tübingen: Ed. Instituto Geográfico, p. 53-84, 2000.

KOHLHEPP, G. Erneuerbare Energien und Biokraftstoffe in Brasilien: Ethanolproduktion als Erfolgsmodell des Agrobusiness. In: HOFFMANN, K.-D.; ZIRKL, F. (org.) Brasilien in der Ära Lula: neue Entwicklungsszenarien im Land der Zukunft? Eichstätt (em impressão), 2013.

KOHLHEPP, G.; SCHRADER, A. (org.) Homem e natureza na Amazônia: hombre y naturaleza en la Amazonia. Tübinger Beiträge zur Geographischen Lateinamerikaforschung (= TBGL N. 3). Tübingen: Ed. Instituto Geográfico, 1987.

KOHLHEPP, G.; BLUMENSCHEIN, M. Südbrasilianer als Akteure beim ländlichen Strukturwandel im brasilianischen Mittelwesten: das Beispiel Mato Grosso. In: ESCHENBURG, R. et al. (org.) Lateinamerika: Gesellschaft, Raum, Kooperation. Frankfurt am Main: Vervuert, p. 65-84, 1999.

KOHLHEPP, G.; COY, M. Amazonien: Vernichtung durch Regionalentwicklung oder Schutz zur nachhaltigen Nutzung? In: COSTA, S.; KOHLHEPP, G.; NITSCHACK, H.; SANGMEISTER, H. (org.) Brasilien heute: Geographischer Raum, Politik, Wirtschaft, Kultur (Brasil hoje: espaço geográfico, política, economia, cultura) (= Bibliotheca Ibero-Americana N. 134). Frankfurt am Main: Vervuert, p. 111-134, 2010.

LEHMANN, E. Historische Züge der Landesentwicklung im südlichen Brasilien (= Wiss. Veröffentl. d. Deutschen Inst. f. Länderkunde N. F. 15/16). Leipzig, p. 51-93, 1958.

LÜCKER, R. Agrarräumliche Entwicklungsprozesse im Alto UruguaiGebiet (Südbrasilien) (Desenvolvimento agrário na região do Alto Uruguai). Tübinger Beiträge zur Geographischen Lateinamerikaforschung (= TBGL N. 2). Tübingen: Ed. Instituto Geográfico, 1986.

MAACK, R. Die neu erschlossenen Siedlungsgebiete und Siedlungen im Staate Paraná. Ibero-Amerika-Archiv, 2 (11), p. 208-248, 1937.

MANSHARD, W. Einführung in die Agrargeographie der Tropen (Introdução à geografia agrária dos trópicos). Mannheim: Bibliograph. Institut, 1968. 
MARTIN, G. The life and thought of Isaiah Bowman. Hamden; Conn: The Shoe String Press, 1980.

MAULL, O. Brasilien. In: KLUTE, F. (Org.): Handbuch der geographischen Wissenschaft: Südamerika. Potsdam: Athenaion, p. 146-269, 1930a.

MAULL, O. Vom Itatiaya zum Paraguay: Ergebnisse und Erlebnisse einer Forschungsreise durch Mittel-Brasilien (Do Itatiaia até o Paraguai). Leipzig: K. Hiersemann, 1930b.

MONBEIG, P. Ensaios da geografia humana brasileira. São Paulo: Livr. Martins, 1940.

MONBEIG, P. Pionniers et planteurs de 1'État de São Paulo. Paris: Armand Colin, 1952.

MONBEIG, P. (1991): Aula magna: pour le cinquantenaire de l'Université de São Paulo. In: THÉRY, H.; DROULERS, M. (org.) Pierre Monbeig. Paris: IHEAL, p. 227-231, 1991.

NEUBURGER, M. Pionierfrontentwicklung im Hinterland von Cáceres (Mato Grosso, Brasilien): ökologische Degradierung, Verwundbarkeit und kleinbäuerliche Überlebensstrategien (Desenvolvimento da frente pioneira no binterland de Cáceres, Mato Grosso). Tübinger Beiträge zur Geographischen Lateinamerikaforschung (= TBGL N. 23). Tübingen: Ed. Instituto Geográfico, 2002.

PAFFEN, K. H. Caatinga, Campos und Urwald in Ostbrasilien: ein Beitrag zum Savannenproblem. In: Tagungsberichte $\mathbf{u}$. Wissenschaftliche Abhandlungen (= Deutscher Geographentag Hamburg 1955). Wiesbaden: Franz Steiner, p. 214226, 1957.

PFEIFER, G. Die Bedeutung der "frontier" für die Ausbreitung der Vereinigten Staaten bis zum Mississippi. Geogr. Zeitschrift, 41, p. 138-158, 1935.

PFEIFER, G. Das wirtschaftsgeographische Lebenswerk Leo Waibels. Erdkunde, 6 (1), p. 1-20, 1952a.

PFEIFER, G. Brasiliens Stellung in der kulturgeographischen Entwicklung der Neuen Welt (Kolonialzeit). Erdkunde, 6 (2), p. 85-103, 1952 b. 
PFEIFER, G. Landwirtschaftliche Betriebssysteme und Kolonisationserfolg in Südbrasilien aufgrund der Forschungen von Leo Waibel. Erdkunde, 7 (4), p. 241 249, 1953.

PFEIFER, G. Leo Waibels Arbeiten zur Kolonisation in Südbrasilien. In: WAIBEL, L. Die europäische Kolonisation Südbrasiliens (= Colloquium Geographicum N. 4). Bonn: Ferd. Dümmlers, p. 7-18, 1955.

PFEIFER, G. Städtische und ländliche Bevölkerung in Brasilien und die Binnenwanderungsbewegung. Geogr. Taschenbuch 1956/57. Wiesbaden: Franz Steiner, p. 392-402, 1956.

PFEIFER, G. Brasília. In: LEIDLMAIR, A. (org.) Hermann von WissmannFestschrift. Tübingen: Selbstverlag Geogr. Institut, p. 289-320, 1962.

PFEIFER, G. Carl Ortwin Sauer. Geographische Zeitschrift, 53 (1), p. 1-9, 1965.

PFEIFER, G. Kontraste in Rio Grande do Sul: Campanha und Alto Uruguai. Geographische Zeitschrift, 55 (3), p. 163-206, 1967.

PFEIFER, G. (org.) Symposium zur Agrargeographie anlässlich des 80. Geburtstags von Leo Waibel am 22.02.1968 (= Heidelberger Geogr. Arb. N. 36). Heidelberg (cooperação de G. Kohlhepp, H.-J. Nitz, A. Scheuerbrandt), 1971.

PFEIFER, G.; KOHLHEPP, G. Wirtschafts- und sozialgeographische Studien in Südbrasilien (Estudos de geografia econômica e social no Sul do Brasil) (= Relatório de Pesquisas hectogr. inédito). Heidelberg, p. 1-129, 1966.

PFEIFER, G.; KOHLHEPP, G. (Org.) Leo Waibel als Forscher und Planer in Brasilien: vier Beiträge aus der Forschungstätigkeit 1947-1950 (Leo Waibel como pesquisador e planejador no Brasil) (Trad. G. Kohlhepp). Erdkundliches Wissen, N. 71 (= Geogr. Zeitschrift. Beihefte). Wiesbaden; Stuttgart: Franz Steiner, 1984.

ROCHE, J. La colonisation allemande et le Rio Grande do Sul (= Travaux et Mémoires de l'Institut des Hautes Études de l'Amérique Latine III). Paris: IHEAL, 1959.

SCHMIEDER, O. The Brazilian culture hearth. Univ. of California Public. in Geography, 3 (3), p. 159-198, 1929.

SCHMIEDER, O. Länderkunde von Südamerika (Geografia regional da América do Sul). Wien: Franz Deuticke, 1932. 
SCHMIEDER, O. Lebenserinnerungen und Tagebuchblätter eines Geographen (Lembranças e diário de um geógrafo). Kiel: Ferd. Hirt, 1972.

STERNBERG, H. O'Reilly. The status of geography in Brazil. The Professional Geographer, N. S. 3 (3), p. 23-29, 1951.

STERNBERG, H. O’Reilly. A água e o homem na Várzea do Careiro. Rio de Janeiro: Museu Paraense E. Goeldi, 1956/1998 (1998: 2v.; vol. II: mapas).

STERNBERG, H. O'Reilly. Address by the Executive Secretary of the Brazilian National Committee of the IGU. In: Comptes Rendus du XVIIIe Congrès Intern. de Géographie, tome 1. Rio de Janeiro: IGU, p. 167-177, 1959.

STERNBERG, H. O'Reilly. The Amazon river of Brazil. Erdkundliches Wissen, N. 40 (= Geogr. Zeitschrift. Beihefte). Wiesbaden: Franz Steiner, 1975.

THÉRY, H.; DROULERS, M. (org.) Pierre Monbeig: un géographe pionnier (= Travaux et Mémoires de L'IHEAL N. 55, Série Essais 11). Paris: IHEAL, 1991.

VALVERDE, O. The Southern Plateau: Excursion Guidebook 9. 18 ${ }^{\text {th }}$ Intern. Geogr. Congress. Rio de Janeiro: IGU, 1957.

VALVERDE, O. Geografia agrária do Brasil. Rio de Janeiro, Inst. Nac. Estudos Pedagógicos, 1964.

VALVERDE, O. Der Beitrag Leo Waibels zur brasilianischen Geographie. In: PFEIFER, G. (org.) Symposium zur Agrargeographie (= Heidelberger Geogr. Arb. N. 36). Heidelberg, p. 120-128, 1971a.

VALVERDE, O. Shifting cultivation in Brazil: ideas on a new land policy. In: GLASER, G. (org.) Beiträge zur Geographie Brasiliens (= Heidelberger Geogr. Arb. N. 34). Heidelberg, p. 1-17, 1971 b.

VALVERDE, O. (org.) A organização do espaço na faixa da Transamazônica (v.1/v.2: Acre e regiões vizinhas). Rio de Janeiro, 1979/1989.

VALVERDE, O. Estudos de geografia agrária brasileira. Petrópolis: Vozes, 1985.

VALVERDE, O. Grande Carajás: planejamento da destruição. Rio de Janeiro, 1989.

VIEIRA, F. Escolha do sítio para Brasília. Boletim Geográfico, N. 150, 1959. 
WAGEMANN, E. Die deutschen Kolonisten im brasilianischen Staate Espírito Santo (Os colonos alemães no Espírito Santo, Brasil). München; Leipzig: Duncker \& Humblot, 1915.

(*) WAIBEL, L. Die wirtschaftsgeographische Gliederung Mexikos. Geographische Zeitschrift, 35, p. 416-439, 1929.

WAIBEL, L. Die Rohstoffgebiete des tropischen Afrika (As regiões de matérias primas da África tropical). Leipzig: Bibliograph. Inst., 1937.

WAIBEL, L. White settlement in Costa Rica. Geogr. Review, 29 (4), p. 529-560, 1939.

WAIBEL, L. Report on my research investigations on "Settlement possibilities in Central America" for the Academic Year 1945-46 (3 pp. hectogr.) (RF 45:19). Madison, Wisc., 1946.

WAIBEL, L. Uma viagem de reconhecimento ao Sul de Goiás. Revista Brasileira de Geografia, 9 (3), p. 313-342, 1947 a.

WAIBEL, L. Rundschreiben über meine Reisetätigkeit im Jahre 1947 (01.10.1947) (3 pp. hectogr.). 1947b.

WAIBEL, L. A vegetação e o uso da terra no Planalto Central (Trad. Vegetation und Landnutzung auf dem Planalto Central. In: PFEIFER; KOHLHEPP, 1984, p. 9-32). Revista Brasileira de Geografia, 10 (3), p. 335-380, 1948a.

WAIBEL, L. A teoria de von Thünen sobre a influência da distância do mercado relativamente à utilização da terra (sua aplicação à Costa Rica). Revista Brasileira de Geografia, 10 (1), p.1-40, 1948 b.

WAIBEL, L. A elaboração de um novo mapa de vegetação do Brasil. Revista Brasileira de Geografia, 10 (2), p. 301-304, 1948c.

WAIBEL, L. Contribuição ao problema da mudança da capital. O Jornal (Rio de Janeiro), 19.12 .1948 (reedição em Boletim Geográfico, 19 (164), 1961, p. 612617), $1948 d$.

WAIBEL, L. Tagebuch Teil IV 1948: Reise nach Rio Grande do Sul 1948 (Diário da viagem ao Rio Grande do Sul) (cópia datilografada), p. 416-469, 1948e.

WAIBEL, L. Tagebuch Teil V 1948: Reise in Paraná 1948 (Diário da viagem ao Paraná) (manuscrito original), p. 70-639, $1948 f$. 
WAIBEL, L. Princípios da colonização européia no Sul do Brasil (Trad. Die Grundlagen der europäischen Kolonisation in Südbrasilien. In: PFEIFER; KOHLHEPP, 1984, p. 33-76). Revista Brasileira de Geografia, 11 (2), p. 159222, 1949.

WAIBEL, L. O que aprendi no Brasil (Trad. Was ich in Brasilien lernte. In: PFEIFER; KOHLHEPP, 1984, p. 105-117). Revista Brasileira de Geografia, 12 (3), p. 419-428, 1950.

WAIBEL, L. A colonização dos Campos do Estado do Paraná. In: C. R. Congr. Intern. de Géographie, Lisbonne 1949, t. IV, p. 61-66. Lisbonne: IGU, 1952.

WAIBEL, L. Die europäische Kolonisation Südbrasiliens (A colonização européia no Sul do Brasil) (redação e prefácio de G. Pfeifer) (= Colloquium Geographicum N. 4). Bonn: Ferd. Dümmlers, 1955a.

WAIBEL, L. As zonas pioneiras do Brasil (Trad. Die Pionierzonen Brasiliens. In: PFEIFER; KOHLHEPP, 1984, p. 77-104). Revista Brasileira de Geografia, 17 (4), p. 389-422, $1955 \mathrm{~b}$.

WAPPÄUS, J. E. Handbuch der Geographie und Statistik des Kaiserreichs Brasilien (Manual da geografia e estatística do Império do Brasil). Leipzig: Hinrichs, 1871.

WILHELMY, H. Probleme der Urwaldkolonisation in Südamerika. Zeitschr. d. Ges. f. Erdkunde zu Berlin, 75 (7/8), p. 303-314, 1940.

WILHELMY, H. Das große Pantanal in Mato Grosso: ein Beitrag zur Landeskunde tropischer Schwemmlandebenen (= Tagungsber. u. wiss. Abhandl. d. 31. Deutschen Geographentags in Würzburg 1957). Wiesbaden: Franz Steiner, p. 45-71, 1958.

WILHELMY, H. Tropische Transhumance: Beobachtung auf einer Amazonasreise mit G. Pfeifer und H. Lehmann. Heidelberger Studien zur Kulturgeographie (= Heidelberger Geogr. Arb. N. 15). Wiesbaden: Franz Steiner, p. 188-207, 1966.

WILLEMS, E. A aculturação dos alemães no Brasil (= Brasiliana N. 250). São Paulo: Cia. Ed. Nacional, 1946. 
* Para a bibliografia completa e as apreciações de Leo Waibel vide PFEIFER, G.; KOHLHEPP, G. (org.) Leo Waibel als Forscher und Planer in Brasilien: vier Beiträge aus der Forschungstätigkeit 1947-1950 (Leo Waibel como pesquisador e planejador no Brasil) (Trad. G. Kohlhepp). Erdkundliches Wissen, N. 71 (= Geogr. Zeitschrift. Beihefte). Wiesbaden; Stuttgart: Franz Steiner, p. 118-123, 1984.

Endereço para correspondência:

Gerd Koblhepp-gerd.kohlhepp@t-online.de Im Kleeacker, 12

D-72072 Tübingen, Alemanha 